\title{
Transformación y final de las villae en occidente (siglos IV-VIII): problemas y perspectivas
}

\author{
Gisela Ripoll * \\ Javier Arce ***
}

\begin{abstract}
RESUMEN
Análisis de las transformaciones que experimentan las uillae romanas en el occidente romano durante la antigüedad tardía comparando y contrastando la evidencia literaria y arqueológica y considerando las distintas interpretaciones dadas por historiadores y arqueólogos a este fenómeno.
\end{abstract}

PALABRAS CLAVE: Transformaciones. Uillae. Occidente. Antigüedad tardía.

\begin{abstract}
Analysis of the transformations that Roman uillae underwent in the Roman West in the Late Roman period comparing and contrasting the literary and the archaeological evidence and thus considering the differing interpretations given by historians and archeologists to this phenomenon.
\end{abstract}

KEY WORDS: Transformations. Uillae. Roman West. Late Antiquity.

\section{PRESENTACIÓN DE LA PRO- BLEMÁTICA Y LÍMITES DEL TEMA}

Líneas de investigación recientes sobre el final de las uillae ${ }^{2}$ y de los establecimientos rura$l \mathrm{~s}^{3}$ del mundo romano permiten comprobar que los grandes complejos arquitectónicos rurales, uillae señoriales y aristocráticas tienen cons- tatada una pervivencia mayor a aquella que tradicionalmente se había considerado siendo usados y reutilizados hasta momentos muy avanzados como son los siglos VI y VII. El estudio de estas transformaciones de las uillae en el Occidente romano en el periodo tardo-romano es una empresa imposible dentro de los límites de un trabajo como este. Aquí, por

* Universidad de Barcelona.

** Université March Bloch, Estrasburgo.

Agradecemos a G. P. Brogiolo, G. Cantino-Wataghin, A. Chavarría y especialmente a C. Balmelle las sugerencias y aportaciones bibliográficas. Algunas informaciones de C. Balmelle son fruto de su libro: Les demeures aristocratiques dans le Sud-Ouest de la Gaule, de la Tétrarchie au début de l'époque franque, Mémoire de Synthèse en vue de l'Habilitation à diriger des recherches, Université de Paris IV-Sorbonne (París, 1995) (Supplément Aquitania, en prensa).

2 Sobre la definición, los límites del término y la notable diversidad de tipos de uillae, cf. Ph. Leveau, "La ville antique et l'organisation de l'espace rural: villa, ville, village", Annales 38 (1983), 2, pp. 920-94I, y A. Carandini, "La villa romana e la plantagione schiavistica", Storia di Roma, 4. Caratteri e morfologie, ed. G. Einaudi (Turín, 1989), pp. I0।-200.

3 Se entiende por establecimiento rural una gran variedad de estructuras que no pueden ser incluidas dentro de un único tipo o categoría arquitectónica. Esta variabilidad es la que induce a la prudencia en el momento de hablar de establecimientos rurales. Cf. Paul van Ossel, Établissements ruraux de l'Antiquité tardive dans le nord de la Gaule (Suppl. Gallia 5I, París, 1992). 
tanto, se podrán dar solamente unas indicaciones genéricas y se presentarán una serie de ejemplos que configuran unos modelos-tipo de los fenómenos acaecidos, aunque no son aplicables a todos los casos -numerosos- que pudieron darse.

Sin embargo, el estudio de este problema es una excelente oportunidad para contrastar la documentación literaria y la documentación arqueológica, y, consiguientemente, para observar las distintas interpretaciones dadas por historiadores y por arqueólogos ante el fenómeno. Las discrepancias son muchas y más aún si se piensa que es en el campo arqueológico donde queda mucho por hacer. Aún a riesgo de la provisionalidad nos atrevemos aquí a afrontar el problema sin pretender ni la exhaustividad ni las conclusiones definitivas. Como ocurre en el caso de las ciudades, el estudio de la evolución y transformación o final de las uillae presenta desarrollos diferentes según los lugares, los contextos y las particularidades regionales y presenta igualmente una serie de problemas colaterales - de tipo social y económico- que no podremos abordar aquí.

El problema de la terminología y de la evolución del significado uillalae resulta fundamental y previo a cualquier estudio que aborde esta problemática. Aquí solo podremos hacer al respecto algunas precisiones. Por una parte la literatura tardía se detiene en la descripción de las uillae de modo tópico y anticuario y es más parca en lo que se refiere a su transformación, destrucción o desaparición. La utilización de uilla durante la antigüedad tardía no se refiere a lo que normalmente se entiende por este tipo de construcción, es decir un sector residencial -pars urbana- y otro agrario -pars rustica. A partir de mediados del siglo VI, la palabra uilla no sólo define la edificación residencial, sino también el conjunto de propiedades que de ella dependen, e incluso puede llegar a designar un núcleo de hábitat, una domus, un mansus o un casale ${ }^{4}$.

Para un autor como Paladio, escribiendo a fines del siglo IV d.C., el edificio rural que sirve de habitación al propietario de una tierra, se denomina praetorium, término que contrasta significativamente con el que utiliza Columela, en la primera mitad del siglo I d.C., que lo denomina uilla (Pal. Op. Agr. 1,7; Colum. Re rust. $5,2)$. Praetorium es un vocablo tomado de la esfera militar que, en cierto modo, implica una fortificación o un aspecto exterior fortificado ${ }^{5}$.

Signo preciso de la inseguridad de los tiempos, el uso de praetorium, como igual o sinónimo de uilla encuentra en la iconografía de las uillae que aparecen en los mosaicos de pavimento, una confirmación precisa ${ }^{6}$ y se ve también constatado en las excavaciones aqueológicas como es el caso, en Hispania, de las uillae de Carranque (próxima a Toletum) o Pedrosa de la Vega, en la actual provincia de Palencia, en la meseta castellana.

A comienzos del siglo $V$, en el año 4I7, el presbítero Consencio describe, en una epístola a su corresponsal Agustín, las peripecias de los priscilianistas en la provincia Tarraconense y se refiere a la propiedad de un tal Severus como su castellum, que estaba situado en las cercanías de Hilerda (actual Lleida/Lérida) (Aug. Ep. II,I-4) ${ }^{7}$. Castellum es aquí sinónimo de uilla, sin duda. Debemos imaginar el paisaje rural de la antigüedad tardía plagado de estos conjuntos arquitectónicos en forma de enclaves fortificados, urbes in rure, residencias de propietarios, explotaciones agrícolas que proporcionan subsistencia y seguridad a la pobla-

\footnotetext{
4 D. Claude, "Haus und Hof im Merowingerreich nach den erzählenden und urkundlichen Quellen”, Bericht über zwei Koloquien der Kommission für die Altertumskunde Mittel-und Nordeuropas von 24. bis 26. Mai 1990 und 20. bis 22. November 1991 (34. und 35. Arbeitstagung) (Göttingen, 1997), pp. 321-334, clarifica toda esta problemática a partir de un análisis minucioso de las fuentes de este periodo.

5 Comentarios sobre el tema en R. MacMullen, Soldier and Civilian in the Later Roman Empire (Harvard, 1967) p. 42 y ss.

6 Sobre el tema, entre otros, ver T. Sarnowski, Les représentations de villas sur les mosaïques africaines tardives (Varsovia, 1978) con M. Nowicka, Les maisons à tours dans le monde grec (1975).

7 CSEL, 88 (|98I).
} 
ción de colonos, uilici o agricultores que habitaban, a su vez, en pequeños establecimientos o construcciones rurales que no deben ser interpretados como uillae.

Ahora bien; ya Isidoro identifica uilla con una tierra, con una posesión de una extensión de terreno: uilla a uallo, id est agere terrae, nuncupata, quod pro limite constitui solet ${ }^{8}$, lo que indica que, a partir del siglo VI, la palabra uilla no solo define la edificación residencial, sino también el conjunto de propiedades que de ella dependen, e incluso llega a designar un núcleo de hábitat, una domus o un casale.

También los estudios realizados sobre los textos de Gregorio de Tours permiten observar de nuevo como el término uilla responde a realidades diversas ${ }^{9}$. El significado más común es el de una circunscripción administrativa relativa a un grupo humano con un fisco común para diversos propietarios. Sin embargo uilla se refiere también a una domus, a un conjunto de tierras del tipo res, o a una casa y las tierras que la circundan. El mismo problema se encuentra en la utilización del término mansus en el siglo VII, puesto que designa lo mismo que uilla en la obra de Gregorio de Tours.

La arqueología ha querido precisar más esta documentación textual. Así, J. G. Gorges considera que una uilla es un yacimiento privilegiado con una superficie media entre 0.5 y 3.5 ha más, al menos, dos elementos arquitectónicos significativos y otros agrícolas bien diferenciados $^{10}$. De todo esto se deduce, como hemos apuntado antes, que de los muchos yacimientos detectados no todos merecerían el calificativo o definición de uillae y, aunque no vamos a referimos a ellos aquí, sí debería tenerse en cuenta también su evolución, transformación o desaparición, ya que son estructuras rurales que suelen formar parte de la esfera de la uilla como unidad de producción agrícola.

Teniendo en cuenta estas definiciones y acepciones se pasa ahora al tema de estudio, centrándolo esencialmente en la problemática de la pars occidentis, puesto que las lagunas que presenta la investigación de la pars orientis todavía son más importantes "'. Si bien los estudios sobre las uillae durante la antigüedad tardía '2, desde su arquitectura hasta su decoración, han sido objeto de numerosas publicaciones, al igual que lo han sido los establecimientos rurales, el momento final de estas estructuras ha retenido la atención de muy pocos investigadores. Una excepción es un recurrido texto de Simon P. Ellis ${ }^{13}$, basado en las "subdivisiones" o compartimentaciones de los espacios que se producen entre los siglos IV al VI, tomando ejemplos en su mayoría de edificios públicos situados en ámbitos urbanos. Este fenómeno lleva a este investigador a observar una degradación urbana generalizada que lleva a la presencia de "squatters", si se permite el término, a la vez que se da un amplio desarrollo de la arquitectura privada, centrado sobre todo en la construcción de villae o edificios rurales ${ }^{14}$. Si bien estas aportaciones, pueden ser actualmente matizadas y requieren una larga discusión, es muy cierto y se está comprobando cada vez

\footnotetext{
8 Etym. 15, 13.

9 El estudio particular de M. Heinzelmann, "Villa d'après les oeuvres de Grégorie de Tours", Aux sources de la gestion publique. I. Enquête lexicographique sur fundus, villa, domus, mansus, ed. E. Magnou-Nortier, (Collection UL3, Lille, 1993), pp. 45-70, incide sobre estos problemas e identifica, por regla general, uilla con village. Se recogen aquí sus principales conclusiones.

10 J. G. Gorges, Les villas hispano-romaines. Inventaire et problematique archéologiques (París, 1979) p. 16.

II Sobre este tema ver las interesantes consideraciones de J. J. Rossiter, "Roman villas of the Greek East and the villa in Gregory of Nissa Ep. 20", Journal of Roman Archaeology 2 (Michigan, 1997), pp. I0I-I 10.

12 A nivel global y como último estado de la cuestión, véase J. Arce, "Otium et negotium: the great estates, 4th-7th century", The Transformation of the Roman World AD 400-900, L. Webster y M. Brown (ed.), (British Museum, Londres, 1997), pp. 19-32.

13 S. P. Ellis, "The End of the Roman House", American Journal of Archaeology 92 (1988), pp. 565-579.

14 Sobre la implantación de la arquitectura y los espacios de recepción véase de este mismo autor: S. P. Ellis, "Power, Architecture and Decor: How the late Roman Aristocrat Appeared to His Guests", Roman Art in the Private Sphere. New Perspectives on the Architecture and Decor of the Domus, Villa and Insula, E. R. Gazda (ed.), (The University of Michigan, 1991), pp. II7-I33.
} 
más arqueológicamente, que existe una fragmentación de los espacios en ámbito urbano, no sólo de los edificios públicos, sino también de los privados. Por ejemplo, las casas de Efeso sufren múltiples adaptaciones y readaptaciones hasta entrado el siglo VII, muestra de una necesidad para dar cabida a un mayor número de inquilinos. En el caso de Roma, los comportamientos son muy variados y deben ser contrastados con las descripciones que proporcionan Olympiodoro y otros autores sobre la riqueza espectacular de ciertas domus romanas, puesto que se sabe de la decadencia y el abandono total de algunas de ellas en el siglo $\mathrm{VI}$, al igual que se sabe, tal como se verá mas adelante de las donaciones efectuadas a la Iglesia, gracias en muchos casos al Liber Pontificalis. Las casas de Ostia, también plantean situaciones semejantes, a las que se suman los problemas de tipo ecológico, como por ejemplo las marismas, etc., y los directamente relacionados con el comercio y la annona, principales causantes del fin de la razón de ser de la ciudad. Otros ejemplos que deben ser también analizados se encuentran por ejemplo en las casas de Apamea y en el Agora de Atenas.

Desde hace algunos años se documenta un interés creciente por el tema de las transformaciones de las uillae que conducirá a trabajos como el de Paul van Ossel Etablissements ruraux de l'Antiquité tardive dans le Nord de la Gaule ${ }^{15}$. Las únicas publicaciones recientes que además de aportar datos nuevos, contienen una reflexión sobre el final de las uillae son las editadas por Gian Pietro Brogiolo sobre Edilizia residenziale tra $\mathrm{V}$ e VIII secolo ${ }^{16}$ y La fine delle ville romane ${ }^{17}$ resultado de dos reuniones de trabajo. Cabe citar también otros textos que sin intentar dilucidar el problema, sí ejemplifican muchas de las cuestiones que aquí van a ser tratadas; principalmente el volumen L'environnement des églises et la topographie religieuse des campagnes médiévales fruto de un congreso celebrado en 1989 18; algunos trabajos incluidos dentro del coloquio L'habitat rural du haut Moyen-Âge (France, Pays-Bas, Danemark et Grande-Bretagne), editado por C. Lorren y P. Périn y publicado en 1995 en Rouen ${ }^{19}$; y un largo compendio debido a Jean-Pierre Sodini ${ }^{20}$.

Hemos de suponer que las uillae romanas en el siglo IV estaban ocupadas por propietarios romanos, ricos o menos ricos, possessores de estas tierras, gestionadas por sus correspondientes colonos, visitadas esporádicamente por ellos, pero indudablemente fuente de su riqueza y patrimonio. Ahora bien, ¿qué sucedió con la llegada de nuevos inquilinos "bárbaros" a quienes se conceden tierras en virtud de acuerdos o pactos o simplemente por apropiación forzosa? Un tema crucial es saber si esta nueva distribución y presencia significó o fue la causa de la desaparición o transformación de las uillae, tanto en su aspecto físico como en el modo de producción y explotación. En definitiva, se trataría de averiguar si el cambio de propietario implicó un cambio en el uso dado a la uilla, o significó el abandono de su anterior propietario; y también si hubo una cambio en el modo de explotación de la misma. Conviene, igualmente, determinar si estos nuevos inquilinos se instalaron exclusivamente en las uillae ya existentes o también lo hicieron en las ciudades, aunque pasasen a controlar o percibir una parte de la producción. ¿Fue este hecho el origen del abandono por parte de sus antiguos propietarios de sus pose-

\footnotetext{
15 Publicado en Gallia, Suppl. 5 I (París, 1992).

16 Edilizia residenziale tra V e VIII secolo. $4^{\circ}$ Seminario sul tardoantico e l'alto Medioevo in Italia centrosettentrionale, Monte Barro-Galbiate (Lecco) 2-4 settembre 1993, G.P. Brogiolo (ed.), (Documenti Archeologia 4, Mantua, 1994).

17 La fine delle ville romane: transformazioni nelle campagne tra tarda Antichità e alto Medioevo. $1^{\circ}$ Convegno Archeologico del Garda, Gardone Riviera (Brescia) 14 ottobre 1995, G.P. Brogiolo (ed.), (Documenti Archeologia II, Mantua, 1996).

18 L'environnement des églises et la topographie religieuse des campagnes médiévales, Actes du Ille congrès international d'archéologie médiévale, Aix-en-Provence, 28-30 septembre 1989, M. Fixot y E. Zadora-Rio (eds.), (Documents d'Archéologie Française 46, París, 1994).

19 A este volumen hay que sumar el artículo de C. Lorren y P. Périn "Images de la Gaule rurale au Vle siècle", Grégoire de Tours et I'espace gaulois. Actes du Congrès International (Tours 3-5 Novembre 1994), N. Gauthier y H. Galinié (eds.) (Tours, I997), pp. 93- 109.

20 J.-P. Sodini, "Habitat de l'Antiquité Tardive", Topoi 5/I (I995), pp.I5I-2I8.
} 
siones, que prefirieron perder sus bienes trasladándose a otros lugares más seguros a fin de no verse sometidos al control y contribución a las poblaciones recién llegadas? Arqueológicamente es muy difícil detectar estos hechos o contestar con certeza a estas preguntas. La arqueología, el análisis arqueológico, puede detectar, sin embargo, otros problemas y, eventualmente, constatar hechos como los que a continuación planteamos en forma de cuatro preguntas o grandes enunciados, teniendo siempre en cuenta que los comportamientos rurales varían considerablemente dependiendo de las características propias de cada zona, región o provincia del Imperio. Tampoco se puede obviar que la uilla es uno de los elementos esenciales -junto con la centuriación y los uicien la vertebración del paisaje rural de época romana a la vez que reflejo no sólo de todo un sistema económico y cultural, sino también de un sistema de explotación agrícola ${ }^{21}$.

La primera cuestión plantea el problema de cómo los establecimientos rurales y las uillae, pasan en un momento determinado a obliterar una parte de sus estructuras transformando el uso original, y el porqué otros son abandonados definitivamente. En segundo lugar se cuestiona cuándo se produce este proceso de cambio o modificación de la estructura. A continuación cabe interrogarse acerca del porqué existen estas transformaciones, es decir cuáles son los factores que intervienen en los cambios y si estos tienen relación con la economía, la propiedad y la modificación en el sistema de explotación. Se deben discutir también algunos de los tópicos ya habituales en la bibliografía sobre el declive y abandono gradual de la vida urbana. Por último, es necesario plantear si la uilla y las diferentes propiedades territoriales de un mismo dominus -si las tiene- son abandonadas o totalmente transformadas. A partir de ahí surge el problema de qué es lo que ocurre con el propietario y su familia, reflexionando sobre la difícil cuestión del desplazamiento o desaparición de las elites locales, que en definitiva son las mismas elites urbanas.

Sólo después de analizar estas cuestiones podremos plantear si del estudio deriva o no un modelo en el sistema de ocupación y si éste es válido como hipótesis de partida para un análisis pormenorizado de las diferentes provincias del Imperio. Es evidente que la gran variabilidad regional, los diferentes productos de la explotación y la diversidad de riqueza patrimonial, impide en un principio extraer un modelo prevalente ${ }^{22}$, pero no dejan de existir una serie de fenómenos coincidentes que denotan un trasfondo común.

El análisis arqueológico que aquí se contempla, sólo tiene en cuenta aquellas uillae o establecimientos rurales que han tenido una evolución marcada por una serie de transformaciones. No se analizan aquellas estructuras que han sido simplemente abandonadas, en su mayoría, a lo largo de los siglos $V$ al VII, sin presentar -al menos aparentemente- transformaciones que modifiquen su concepción original.

\section{RESULTADOS DEL PROCESO DE EVOLUCIÓN Y TRANSFORMACIÓN}

La observación y análisis de algunas uillae permite determinar que las estructuras residenciales sufren un proceso evolutivo a veces muy claro que sorprende por su variedad. Gracias a la arqueología estos cambios pueden ser estudiados con mayor atención ${ }^{23}$, puesto que tanto

2l El sistema de explotación y la implantación de una estructura destinada a tal efecto depende esencialmente de las posibilidades que ofrece el propio territorio. M. Le Glay, "La Gaule romanisée", Histoire de la France rurale. I. La formation des campagnes françaises, G. Duby y A. Wallon (eds.) (París, 1975), pp. 203-316, cf. p. 233, esboza un posible modelo interpretativo realizado a partir de un análisis microregional en la Borgoña, que no creemos pueda ser aplicado como modelo de ocupación de tipo global. Por otra parte la relación que se establece entre las uillae y los vici merecería un amplio desarrollo.

22 De cualquier forma esta afirmación viene también dada por la escasa atención que ha merecido hasta el momento la problemática que se plantea en este texto, tal como ya se ha dicho.

23 En J. Percival, The Roman Villa. An Historical Introduction (London, 1976), pp. I83-199 (capítulo sobre "Villas, Churches and Monasteries"), se plantea una primera síntesis sobre las posibles transformaciones. En Arce, "Otium et negotium: the great estates, 4th-7th century", pp. 31-32, existe un esbozo de ellas. 
la moneda y su circulación, como los materiales cerámicos y las remodelaciones de las estructuras murarias, aportan una información cronológica esencial ${ }^{24}$.

La arquitectura residencial evoluciona en muchos casos hacia una reestructuración de sus espacios cambiando su función utilitaria, es decir el concepto planimétrico originario pierde su validez al ser desarticulado. En un principio y siempre teniendo en cuenta que no se ha realizado un análisis exhaustivo, sino un tanteo a modo de hipótesis de trabajo, los diferentes comportamientos observados pueden ser organizados en varias categorías que se comentan a continuación.

\section{Espacios de habitación y recepción transformados en lugares productivos}

Esta categoría contempla espacios de recepción y habitación del propietario y su familia, que en un momento determinado son reestructurados y compartimentados con el fin de convertirse en lugares tipo factoría dedicados a la manufactura y producción de los productos explotados, al igual que al almacenamiento. Es decir, la estructura residencial de la uilla en sí misma se modifica por la de un establecimiento - explotación- rural cambiando claramente la funcionalidad originaria.

En algunos casos la parte residencial no es abandonada o remodelada completamente, algunas habitaciones parece que siguen conservando su destino original, pero otros espacios sí pasan a tener una función destinada cla- ramente a la industria y producción. Se podría hablar por tanto de un mismo conjunto arquitectónico donde se reúnen las necesidades habitativas y de explotación.

Este tipo de comportamiento suele ser muy habitual en la parte occidental del Imperio, aunque su constatación requiere un análisis arqueológico muy depurado, pues en muchos casos las reestructuraciones arquitectónicas son muy difíciles de determinar, a la vez que los materiales arqueológicos al corresponder a períodos avanzados son infravalorados y dificultan una visión global ${ }^{25}$, aunque a veces sí acertada, de la evolución y final de estas estructuras residenciales que pasan a convertirse en establecimientos propiamente rurales. Los pocos estudios detallados que se ocupan de la evolución de la uilla durante la antigüedad tardía, permiten observar que este tipo de conversión y cambio de funcionalidad es un fenómeno relativamente habitual ${ }^{26}$. Estas transformaciones en cada región se mostrarán de una forma diversa atendiendo a dos factores: el sistema de ocupación y explotación territorial precedente y la uilla en sí misma como reflejo del status del propietario ${ }^{27}$.

Un ejemplo localizado en la Italia septentrional es el de Calderara di Reno (Bolonia) ${ }^{28}$. Allí se excavó una uilla que en época tardía fue convertida en factoría, compartimentando y desarticulando los espacios de lo que había sido el sector residencial. El nuevo uso del lugar lo convierte en un establecimiento rural en relación directa con el medio agrícola. Los talleres excavados de fundición, vidrio y metalúr-

\footnotetext{
24 El análisis microregional llevado a cabo por Ch. Pellecuer en la Narbonensis así lo demuestra: Ch. Pellecuer, "Villa et domaine", Le IIle siècle en Gaule Narbonnaise. Données régionales sur la crise de l'Empire, J.-L. Fiches (ed.), Éditions APDCA, (Sophia Antipolis, I996), pp. 277-29I. Lo mismo ocurre en Hispania tal como se comprueba en el Nordeste de la Tarraconensis, cf. el artículo -fruto de un trabajo mucho más amplio- de Alexandra Chavarría, "Transformaciones arquitectónicas de los establecimientos rurales de la antigüedad tardía en el nordeste de la Tarraconensis", Butlletí de la Reial Acadèmia Catalana de Belles Arts de Sant Jordi, I0 (1996), pp. 165-202, y Ead., "Els establiments rurals del llevant de la Tarraconesa durant l'antiguitat tardana: transformacions arquitectòniques i funcionals", Annals de l'Institut d'Estudis Gironins, XXXIX (1998), pp. 9-30.

25 En gran parte debido a la poca espectacularidad de este tipo de documentación, por regla general publicada con poco acierto.

26 No se enumerarán aquí todos los casos conocidos, pero sí algunos ejemplos que muestran este cambio.

27 Estos dos factores señalados por J. Ortalli, "La fine delle ville romane: esperienze locali e problemi generali”, La fine delle ville romane, pp. 9-20, cf. p. 17, deben ser tenidos en cuenta por su importancia para comprender de que tipo de estructura se trata y su posible evolución.

28 Ortalli, “La fine delle ville romane: esperienze locali e problemi generali”, La fine delle ville romane, pp. II-I3.
} 
gia, amplían el abanico de especialidades llevadas a cabo en Calderara ${ }^{29}$.

En Hispania uno de los ejemplos más claros y mejor documentados es el de la uilla de Torre Llauder situada en el suburbium de la antigua ciudad de lluro (actual Mataró) en el levante de la Tarraconensis ${ }^{30}$ (Fig. I). Se trata de una uilla dotada de un edificio de carácter residencial organizado a partir de un peristilo. En un momento posterior al siglo IV se documentan una serie de reformas: el conjunto termal se inutiliza, al menos parcialmente, según evidencian varios muros que aíslan las habitaciones y la obstrucción de los conductos de agua. Una de las habitaciones (núm. 7) se convierte en almacén, encastrándose 18 dolia en el pavimento de mosaico, se construyen dos depósitos revestidos de opus signinum en la habitación contigua (núm. 5) y, en el peristilo (núm. 9) un nuevo depósito que destruye parte del mosaico pavimental anterior.

La uilla de Saint-Clément-La Bichère (VertSaint-Denis, Seine-et-Marne) es un claro ejemplo de continuidad y transformación de un conjunto residencial a una aglomeración dedicada a la explotación industrial, con pervivencias en época carolingia ${ }^{3 !}$. El territorio ocupado por este yacimiento conlleva una pars urbana fechada a partir del siglo I y una pars rustica que inicia su actividad en el siglo II, aunque es posible existiese con anterioridad. En el siglo III se produce una restricción en la ocupación limitada al extremo oriental de la pars rustica y junto a los caminos. El edificio residencial alto impe- rial deja de estar en uso en el siglo IV, sin embargo en la zona central de la uilla a partir de la segunda mitad del siglo IV se documenta una ocupación totalmente diferente. Los pequeños hogares, los hoyos de poste y una gran estructura circular de combustión, testimonian una actividad metalúrgica, cuya cronología viene dada por el hallazgo de un tesoro monetario fechado entre los años 360 y 370. Durante el siglo $\mathrm{V}$ y principios del $\mathrm{VI}$ existe una continuidad en la ocupación del lugar, pero la arqueología no ha podido definir de qué tipo de instalación se trata. De cualquier forma ésta se halla en relación a las estructuras de habitación (fondos de cabaña y hornos domésticos) y de explotación (isecadero de grano o torrefacción?), situadas tanto en este lugar como en la zona norte, que pervivirán hasta la primera mitad del siglo $X$.

\section{La construcción de una iglesia en un sector de la uilla}

La transformación de un sector de una uilla o de una domus urbana en un oratorio privado o en una iglesia, es un fenómeno que se detecta con frecuencia ${ }^{32}$. En algunos cánones de los concilios de Hispania del siglo IV se hace referencia a la existencia de iglesias en uillae o, al menos, de la existencia de lugares de culto en las mismas y en donde se celebraban actos religiosos diversos (Concilio de Toledo I, año 397-400, canon 5 canon 9). La autoridad eclesiástica intentó por todos los medios evitar estos desmanes, ya que sólo se permitía con-

29 Otros ejemplos tomados también de la Italia septentrional y con comportamientos similares al precedente son los de Pontevico y Nuvolento localizados en la llanura de Brescia. F. Rossi, "I casi de Pontevico, Nuvolento e Breno", La fine delle ville romane, pp. 35-4l.

30 M. Ribas, La villa romana de la Torre Llauder de Mataró. Monumento Histórico-Artístico, (Excavaciones Arqueológicas en España, 47, Madrid, 1963). M. Prevosti y F. Clariana, Torre Llauder. Mataró. Villa romana, Guies de Jaciments Arqueològics, (Departament de Cultura de la Generalitat de Catalunya, Barcelona, 1988). El análisis de las transformaciones: J. F. Clariana y M. Prevosti, "Un exemple de ruralització a l'antiguitat tardana: La vil·la de Torre Llauder", III Reunió d'Arqueologia Cristiana Hispànica, Maó, I988, (Barcelona, 1994), pp. I|7-126.

3। La información que sigue procede de A. Koehler, "La villa romaine de Saint-Clément-La Bichère à Vert-Saint-Denis (Seine-et-Marne) au Bas Empire", L'époque romaine tardive en Ile-de-France. Document de Travail n 2. Les campagnes de I'lle-de-France de Constantin à Clovis. Pre-Actes du colloque. Paris, 14-15 décembre 1995, P. Ouzoulias y P. Van Ossel (eds.), (París, I995), pp. 95- II5.

32 Una amplia revisión del fenómeno de la reutilización de estructuras romanas como edificios de culto en G. Cantino Wataghin, “...ut haec aedes Christo Domino in Ecclesiam consecretur. II riuso christiano di edifici antichi tra tarda Antichità e alto Medioevo", XLVI Settimana di Studio del Centro Italiano di Studi sull'Alto Medioevo, t. 2 (Spoleto, 1998), pp. 673-749 (especialmente para la reutilización de estructuras rurales pp. 719-721). 
sagrar iglesias con autorización del obispo y bajo su directo control. La subsistencia del problema en Italia, en la región de Apulia, a fines del siglo $\mathrm{V}$, la tenemos atestiguada en la carta 2 de Gelasio, en la que se trata de solicitar permiso al Papa para hacer un oratorio en una propiedad privada ${ }^{33}$.

Se examinan a continuación algunos ejemplos -que sin ser exhaustivos- permiten observar cómo se produjo la transformación desde el punto de vista arqueológico. Vale decir que se debe trabajar con prudencia puesto que tal como ya señaló P. A. Février, la continuidad entre una uilla y una iglesia, puede ser tan sólo un fenómeno aparente -al menos en la Provenza- y requiere un análisis minucioso ${ }^{34}$.

Un caso muy claro se encuentra en Hispania en la denominada uilla Fortunatus de Fraga (Huesca, en la antigua provincia Tarraconensis) ${ }^{35}$. El momento de construcción inicial de la uilla se sitúa en el siglo III d.C. El sector residencial se articula a partir del peristilo de 350 $\mathrm{m}^{2}$, alrededor del cual se disponen una serie de salas de recepción y ámbitos domésticos (Fig. 2). Los abundantes mosaicos hallados, y siempre siguiendo criterios estilísticos, definen dos momentos cronológicos ${ }^{36}$. Los de la zona Este con representaciones de Eros y Psique, además de Venus y Eros, serían anteriores -quizá de finales del siglo III o principios del siglo IV- a los del Oeste, donde en los corredores y las habitaciones se recurre a motivos geométricos o animalísticos y vegetales y a motivos característicos cristianos de finales del siglo IV. El mosaico del tablinum llevaba inscrito en el mosaico pavimental, el nombre de Fortunatus y un crismón con el alpha y omega invertidas, fechado hacia finales del siglo IV. La aparición del nombre del propietario, o bien su retrato y el de la domina, es un hecho habitual durante la antigüedad tardía y un medio utilizado por los propietarios para reafirmar su poder. La iglesia situada en el ángulo sudoeste, reutiliza unas habitaciones de este sector de la uilla y en ella se han detectado tres fases constructivas. La primera de ellas corresponde a lo que son las estructuras romanas del siglo IV, es decir, un sector compartimentado en habitaciones, algunas de ellas pavimentadas con mosaicos. La segunda fase constructiva se sitúa a principios del siglo $V^{37}$ y se caracteriza por la instalación de un edificio de carácter cristiano de planta rectangular con tres naves y cabecera tripartita. En la zona central de la cabecera se ubica una pequeña cripta que quizá pueda ser identificada con un martyrium ${ }^{38}$, lo que permite considerar esta fase como la de un oratorium privado. La tercera fase, cronológicamente posterior a mediados del siglo $\mathrm{V}$, implica importantes reformas en la arquitectura del edificio (Fig. 3). La más señalizada es el añadido de un ábside exento, cuadrangular por el exterior y semicircular por el interior, en cuyo centro se instaló el pie de la mesa de altar provisto de un loculus para la

\footnotetext{
33 G. Volpe, Contadini, pastori e mercanti nell'Apulia tardoantica, Edipuglia (Bari, 1996).

34 P.-A. Février, "La marque de l'Antiquité tardive dans le paysage religieux médiéval de la Provence rurale", L'environnement des églises et la topographie religieuse des campagnes médiévales, Fixot y Zadora-Rio (eds.), pp. 27-35, cf. pp. 32-33. El autor, a pesar de la prudencia, está tentado en validar la hipótesis que prácticamente muchos de los prioratos e iglesias de los siglos X al XII encuentran su origen en antiguos lugares de hábitat, ya sean uillae o establecimientos rurales.

35 J. de Serra Ráfols, "La Villa Fortunatus, de Fraga", Ampurias 5 (1943), pp. 5-3I; R. Puertas, "Trabajos de planimetría y excavación en la Villa Fortunatus", Fraga (Huesca), Noticiario Arqueológico Hispánico (1972), pp. 7I-8I. Las planimetrías de las campañas de F. Tuset ( 198 I-1986) fueron publicadas por P. de Palol, "La arqueología cristiana en la Hispania romana y visigoda. Descubrimientos recientes y nuevos puntos de vista", Actes du Xle Congrès International d'Archéologie Chrétienne, Lyon, Vienne, Grenoble, Genève et Aoste, 1986, (Roma, 1989), pp.1975-2022 (cf. pp. 2000-2004). Íd., “Arte y Arqueología", Historia de España Menéndez Pidal, t. III, vol. II, J. Ma Jover Zamora (ed.), España visigoda, (Madrid, I99I), pp. 27I-428, cf. pp. 297-299. Véase también H. Schlunk y Th. Hauschild, Die Denkmäler der frühchristlichen und westgotischen Zeit, (Hispania Antiqua, Maguncia, 1978), pp. I37-I38 y 162 - I63.

36 M. Guardia, Los mosaicos de la Antigüedad tardía en Hispania. Estudios de iconografía, (Barcelona, 1992), pp. 83- 100.

37 La datación viene dada por el material arqueológico fruto de las intervenciones de Puertas, "Trabajos de planimetría y excavación en la Villa Fortunatus", pp. 7I-8I.

38 C. Godoy Fernández, Arqueología y liturgia. Iglesias hispánicas (siglos IV-VIII), Universidad de Barcelona (Barcelona, I995), pp. $227-237$.
} 
deposición de reliquias ${ }^{39}$. También destaca en esta fase la instalación de un baptisterio con ciborium en la zona central de los pies de la iglesia. A partir del siglo VI, las estructuras de la uilla están parcialmente abandonadas y se verán invadidas, al igual que la iglesia, por una serie de inhumaciones.

También la uilla de Sao Cucufate, perteneciente al antiguo territorium de Pax lulia (Beja, Portugal) ${ }^{40}$ constituye otro ejemplo de este tipo de transformación (Fig. 4). A mediados del siglo I d.C. se documenta el primer nivel de ocupación romano que pese a no conocerse con exactitud sus características ha sido denominado uilla I. Estas construcciones fueron rehechas en el segundo tercio del siglo II dando paso a una segunda fase (uilla II). A partir de este momento se establece una primera planificación arquitectónica característica de este tipo de establecimientos con la presencia de una importante zona residencial provista de termas y una pars rustica que irá multiplicando sus edificios con el paso del tiempo. La ocupación de la uilla II, perdurará hasta finales del siglo III o inicios del siglo IV, aunque el abandono no será total, puesto que en la zona occidental de la pars rustica se han documentado materiales de cronología algo posterior. En época postconstantiniana todo el complejo sufre una profunda remodelación que afecta tanto a la zona residencial como a la rústica (uilla III). La primera verá magnificadas sus habitaciones y pondrá los fundamentos de un gran proyecto termal que no llega a materializarse, pero que sin embargo obligó a la completa reestructuración de la pars rustica. La uilla III seguirá en actividad hasta mediados del siglo $\mathrm{V}$. Parece que es en este momento que el tabli- num 4 (de la antigua uilla II) es transformado en iglesia y que empiezan a instalarse tumbas en el deambulatorio del templo pagano -frente a la fachada occidental- que muy posiblemente era ya utilizado para el culto cristiano ${ }^{41}$ (Fig. 5). La hipótesis de trabajo, que no ha podido ser verificada, quiere que las tumbas estén situadas en función de una memoria en la cella del templo. La pregunta es si realmente se trata de la memoria de San Cucufate. La existencia de este edificio de culto cristiano y la conservación en elevación de la uilla III favorecieron la fundación de un monasterio en época medieval, entre el siglo VIII y el siglo XIII ${ }^{42}$ que estuvo en uso hasta mediados del siglo XVI y su iglesia continuó funcionando como capilla rural hasta el siglo XVIII.

No se trata de ejemplos aislados de este tipo de transformación en medio rural. Existen casos bien conocidos, resultado de análisis microregionales, donde la conversión de parte de una uilla en iglesia, es un hecho frecuente como en la zona de Normandía ${ }^{43}$. Sólo a título de ejemplo se puede citar el establecimiento rural de Mondeville (Caën, Calvados) construido a lo largo de los siglos II y III y abandonado durante la antigüedad tardía, puesto que no existe material arqueológico fechable entre el siglo III y el VII. Se trata de un abandono momentáneo, cuya incidencia es desconocida, puesto que hacia la segunda mitad del siglo VII empieza la instalación de las primeras sepulturas y la remodelación de una parte del edificio. Éste se encuentra en el origen de la iglesia de SaintMartin en funcionamiento como parroquia de Mondeville hasta el siglo XII. En la misma Normandía, la iglesia de Saint-Valéry-d'Etretat fechada en el siglo XI y la de Saint-Denis de Lille-

39 N. Duval y J. Fontaine, "Un fructueux échange entre archéologues liturgistes et patristiciens: le colloque de Montserrat (2-5 novembre 78)", Revue des Études Augustiniennes XXV (1979), pp. 265-290.

40 La información que sigue ha sido extraída de la importante publicación de J. de Alarcao, R. Étienne y F. Mayet, Les villas romaines de Sao Cucufate (Portugal), 2 vols. (París, 1990).

4I Se sigue dudando acerca de la exacta cronología de las tumbas, si corresponden a la antigüedad tardía o si bien son de época altomedieval, puesto que habían sido violadas. Alarcao, Etienne y Mayet, Les villas romaines de Sao Cucufate (Portugal), pp. $259-265$.

42 La tradición literaria dice que en época visigoda existía ya un monasterio de la orden de San Benito.

43 Para los ejemplos que siguen a continuación cf. J. Le Maho, "La réutilisation funéraire des édifices antiques en Normandie au cours du haut Moyen-Âge", L'environnement des églises et la topographie religieuse des campagnes médiévales, Fixot y Zadora-Rio (eds.), pp. $10-21$. 
bonne (ambas en Seine-Maritime), con una cronología similar, encuentran su origen en dos uillae respectivamente, aunque es muy posible que la estructura eclesiástica se remonte al siglo VII. Se trata por tanto de ejemplos que muestran la perdurabilidad de las transformaciones arquitectónicas de un hábitat en iglesia con continuidad durante la plena Edad Media.

En la zona sur de la Gallia destaca el ejemplo de la uilla de Séviac (Montreal du Gers, Gers) donde en un momento posterior a mediados del siglo $V$ se llevan a cabo una serie de reformas en la zona sudeste del sector residencial (Fig. 6). Estos cambios implican la instalación de dos edificios de culto uno de ellos aprovechando, en parte, un ámbito de la uilla donde además se instalará un baptisterio provisto de una piscina bautismal circular encastrada en el pavimento de mosaico y el otro construido sobre un antiguo fanum desplazado ligeramente hacia el este. Todo parece indicar que la iglesia construida reutilizando parte de la estructura de la uilla cae en desuso antes que la iglesia construida sobre el fanum cuyo abandono se produce con posterioridad a finales del siglo VII o ya en el VIII según muestra el material numismático documentado en el estrato de cenizas que cubría las estructuras y los depósitos hallados en el interior de varias sepulturas vinculadas a este edificio ${ }^{44}$.

En el valle alto del Ródano, cerca de la actual Ginebra, también se ha podido observar este tipo de comportamiento. Uno de los ejemplos mejor estudiados es el de Satigny ${ }^{45}$ (Fig. 7). Se trata de una uilla bajo imperial que había sido instalada junto a un hábitat precedente. La uilla comportaba dos partes bien diferenciadas por su funcionalidad; una dedicada a la vida cotidiana y otra con una función cultual. Se ha sugerido que el abandono temporal de la uilla es debido a la muerte del propietario ${ }^{46}$ y debe ser puesto en relación con la aparición de la primera tumba en una de las habitaciones con sistema de aire caliente. A partir de este momento empiezan a aparecer una serie de sepulturas y una iglesia construida en madera, que en el siglo VI ocupa toda la superficie edificada. Detrás del ábside de la iglesia se construirá un mausoleo cuadrangular que alberga varias sepulturas. Alrededor del ábside se instalarán algunas tumbas. En la zona meridional se construye un segundo edificio cuyo uso es desconocido. En época carolingia se construye una iglesia en piedra con modificaciones tanto a nivel planimétrico como de elevación, a la vez que se documenta una reorganización cementerial. Es muy posible que la construcción del monasterio en Satigny corresponda a esta misma época. No se trata de un caso aislado en la región de Ginebra, puesto que por ejemplo también Vandoeuvres existe otro caso de instalación de una iglesia sobre una antigua uilla ${ }^{47}$.

Los valles del Mosela y el Saar, conocidos por la abundancia de lujosas uillae, ofrecen también algunos ejemplos de este tipo ${ }^{48}$. Particular interés presenta la discutida uilla de Konz (Kr. Saarburg), correspondiente quizás a la antigua Contionacum, en la confluencia de ambos ríos. Algunos investigadores identifican esta uilla con la residencia de verano del emperador Valentiniano I, a partir de una cita de Ausonio (Mosella, 10,369): fessa sub augustis tu volveret ostia muris ${ }^{49}$. La construcción de esta uilla se inició en la primera mitad del siglo IV y se orga-

\footnotetext{
44 J. Lapart y J. L. Paillet, "Montréal-du-Gers. Lieu-dit Séviac. Ensemble paléochrétien de la villa de Séviac", Les premiers monuments chrétiens de la France, 2, N. Duval (ed.), Picard éditeur (París, 1996), pp. 160-167.

$45 \mathrm{Ch}$. Bonnet, "Les églises rurales de la région de Genève: origines, développement architectural et environnement", in Fixot y Zadora-Rio eds., L'environnement des églises et la topographie religieuse des campagnes médiévales, pp. 22-26, cf. p. 24, figs. I a 4.

46 Afirmación de Bonnet, “Les églises rurales de la région de Genève”, p. 24.

47 Bonnet, "Les églises rurales de la région de Genève", pp. 24-26, figs. 6 a 8.

48 A pesar de la abundancia de uillae en estos valles, y particularmente en la región de Tréveris, la documentación sobre su final es prácticamente desconocida.

49 N. Duval, “Les maisons d'Apamée et l'architecture 'palatiale' de l'Antiquité tardive", IIle Colloque d'Apamée de Syrie, 1980 (Bruselas, 1984), pp. 447-470, cf. p. 466, considera errónea la identificación como residencia imperial.
} 
niza a partir de una planimetría longitudinal con doble fachada y pórtico, además de habitaciones angulares. La gran estructura fue utilizada a lo largo del siglo IV pero su evolución en épocas más tardías es poco conocida ${ }^{50}$. Se desconoce cuánto tiempo pasó entre el abandono de la uilla (si es que realmente fue abandonada) y la creación del núcleo medieval de Konz. Sabemos solamente que el edificio de la uilla debía estar en buen estado cuando sobre ella se instaló la iglesia parroquial de la aglomeración urbana de Konz.

La uilla de Lullingstone (Kent) en Britannia es también un claro ejemplo de cómo la cristianización de los grandes propietarios, en este caso un alto funcionario de la administración provincial, condujo en el siglo IV a la construcción de un oratorio doméstico que se encuentra en el origen de un conjunto eclesiástico múltiple y dinámico ${ }^{5 !}$. La fundación de la uilla se remonta a los años 80-90 d.C. pero a finales del siglo III sufrió una completa reestructuración de ámbitos a la vez que la construcción de un granero de importantes dimensiones. Es en ese momento, o ya muy a principios del siglo IV, en que al norte del conjunto residencial se construyó un mausoleo -donde aparecieron dos sarcófagos en plomoy un templo con cella cuadrada dedicado al culto de las aguas. Este hecho demuestra no sólo una importante aportación constructiva en la uilla sino también una continuidad en determinadas costumbres, como es la asociación al lugar de residencia de un templo y un mausoleo ${ }^{52}$. De cualquier forma la construcción -a finales del siglo IV- del oratorio con pinturas donde se reproducen los retratos de la familia facilitaron no sólo la posterior fundación de una iglesia, sobre la estructura del templo, sino también su paso como propiedad a manos de la Iglesia ${ }^{53}$. Este cambio de propiedad debió acontecer entre principios del siglo $\mathrm{V}$, momento en que se detectan importantes niveles estratigráficos de destrucción y el momento de construcción de la iglesia.

\section{Estructuras monásticas reutilizando sectores de una uilla}

Al estudiar las transformaciones de uillae o establecimientos rurales en iglesias, se han presentado ya algunos casos en que la continuidad se produce en forma de un monasterio. Por tanto es muy probable que entre los ejemplos existan iglesias de carácter monástico ${ }^{54}$.

En primer lugar se tratará un ejemplo interesante situado en Aquitania: la uilla de Plassac (Périgueux), de la que habla un testamento, el de Bertrand, obispo de Mans. El testamento se refiere explícitamente a una uilla donde se construye una iglesia, como ya se ha visto para otros casos. Sin embargo, no se ha podido documentar arqueológicamente hasta qué punto existe una evidente continuidad de ocupación, aunque es muy posible que el sector residencial estuviese abandonado o desocupado a partir del siglo VI. Probablemente la uilla de Plassac corresponde a la de Primuliacum, donde se sabe que Sulpicio Severo retirado a llevar una vida ascética reunió una serie de adeptos. Este retiro se sitúa cronológicamente hacia el año

\footnotetext{
50 K. Goethert-Polaschek, "La villa impériale de Konz", La civilisation romaine de la Moselle a la Sarre. Vestiges romains en Lorraine, au Luxembourg, dans la région de Trèves et en Sarre, Catálogo de la Exposición, (Maguncia, 1983), n² 289, pp. 327-33I.

51 K. S. Painter, "Villas and Christianity in Roman Britain”, G. de G. Sieveking, (ed.), Prehistoric and Roman Studies, (The British Museum, Londres, 197I), pp. I56-175, cf. p. 163. El estudio pormenorizado de la uilla se debe a G. W. Meates, The Roman Villa at Lullingstone, Kent, I, The Site (Monograph Series of the Kent Archaeological Society I, Kent, 1979).

52 Sobre este tipo de asociaciones véanse las diferentes discusiones. En contra: N. Duval, “Existe-t-il une structure palatiale propre à l'Antiquité tardive", Le système palatial en Orient, en Grèce et à Rome, E. Lévy (ed.) (Estrasburgo, 1987), pp. 463-490. A favor: B. Brenk, "Innovation im Residenzbau der Spätantike", Innovation in der Spätantike, B. Brenk (ed.) (Wiesbaden, 1997), pp. 67- II4, cf. pp. 77-79.

53 P. Salway, Roman Britain (Oxford, 1981), p. 601.

54 J. Percival, "Villas and Monasteries in Late Roman Gaul”, Journal of Ecclesiastical History, 48, I (1997) pp. I-2I.
} 
390, cuando tenía unos treinta años ${ }^{55}$. Fundó allí una iglesia, un baptisterio y un monasterio tal como se constata a través de las epístolas de su amigo Paulino de Nola (Ep. 31 . I y 32.7).

También en la Gallia, en Normandía, el ya mencionado análisis microregional ha revelado - gracias a la documentación textual de época medieval- la creación de algunos monasterios sobre una uilla ${ }^{56}$. Todo apunta a que el monasterio de Deux-Jumeaux (Isigny-sur-Mer, Calvados), fuese construido a finales del siglo $\mathrm{VI}$ o principios del siglo VII en las propiedades rurales de una familia aristocrática local que donó sus tierras a San Martin de Vertou. Lo mismo ocurre en la abadía de Cerisy, fundada en época merovingia por Vigor (octavo obispo de Bayeux y contemporáneo a Cildeberto I, 5 | | -5 |8). Las tierras -unas 16.000 ha- fueron donadas por Volusianus, un rico propietario.

En el territorium de Tréveris, del que ya se ha hablado precedentemente, se localiza una uilla con transformaciones importantes hasta convertirla en un monasterio. Se trata de Echternach cuya evolución se puede trazar tanto mediante las fuentes textuales como gracias a la documentación arqueológica ${ }^{57}$. La primera fase constructiva se remonta al siglo I d.C., aunque en el siglo II se realizarán algunas reformas. En el siglo IV se llevan a cabo una serie de importantes reestructuraciones que podrían poner de manifiesto un cambio en la familia propietaria. Los materiales arqueológicos hallados, que pueden fecharse entre finales del siglo IV y mediados del siglo $\mathrm{V}$, abogan por la ocupación del lugar como fortaleza militar. A mediados del siglo VII la propietaria del conjunto, una noble franca llamada Irmina, funda varias iglesias y un monasterio, del cual será abadesa. Muy a finales del siglo VII la documentación textual señala como Irmina donó parte de la uilla Epternacus junto con otras propiedades suyas al obispo Willibrord, quien gracias a otras donaciones por parte de distintos propietarios amplió los territorios del monasterio y lo fue restaurando.

En Italia, uno de los ejemplos más paradigmáticos de una uilla con continuidad en época medieval y con importantes transformaciones hasta constituir un importante conjunto monástico se halla en San Vincenzo al Volturno (Molise) ${ }^{58}$. El primer momento de ocupación del lugar viene documentado en el siglo IV a.C. con la construcción de un pequeño santuario y otras edificaciones de tipo samnita que fueron abandonadas en el curso del siglo III a.C. Cerca de este yacimiento se construyó una uilla con un importante momento de esplendor en el siglo I d.C. y con continuidad hasta el siglo IV. El abandono de esta uilla no acabó con el hábitat bajo imperial de la zona, bien al contrario, una nueva uilla ${ }^{59}$-la denominada uilla tardo-romana- fue construida en una terraza -llamada Colle della Torre- más alta que el antiguo santuario samnita y caracterizada por la construcción de una torre ${ }^{60}$. La situación y

\footnotetext{
55 K. F. Stroheker, Der senatorische Adel im spätantiken Gallien (Tübingen, 1947, reed. Darmstadt, 1970), n 355, p. 216. Sulpicio Severo debió nacer hacia el 360 y se desconoce la fecha de muerte, pero obligatoriamente se sitúa en el primer cuarto del siglo $V$. Pertenecía a una de las grandes familias de Aquitania, nombrado por Gennadius (De vir. ill. 19) como vir genere et litteris nobilis, y se casó con Bassula, perteneciente a una rica familia consular.

56 Le Maho, "La réutilisation funéraire des édifices antiques en Normandie au cours du haut Moyen-Âge", Fixot y Zadora-Rio (eds.), pp. 10-21, cf. p. 14, donde se encuentra toda la bibliografía necesaria y las fuentes textuales que mencionan los ejemplos que se citan a continuación.

57 Para Echternach debe consultarse el sintético pero ilustrativo estudio de J. Metzler, J. Zimmer y L. Bakker, "Die römische villa von Echternach (Luxemburg) und die Anfänge der mittelalterlichen Grundherrschaft", Villa-Curtis-Grangia. Landwirtschaft zwischen Loire und Rhein von der Römerzeit zum Hochmittelalter, W. Janssen y D. Lohrmann (ed.) (Beihefte der Francia II, Munich-Zurich, I983), pp. $29-45$.

58 La bibliografía sobre este yacimiento es amplísima, puesto que el proyecto de investigación de Richard Hodges contempla no sólo la excavación y recuperación de todo el yacimiento, sino también la publicación de los resultados. Un resumen práctico por su carácter general sobre la secuencia arqueológica puede ser consultado en: R. Hodges y F. Marazzi, San Vincenzo al Volturno. Sintesi di storia e archeologia (San Vincenzo, 1995), cf. particularmente pp. 17- 18.

59 Aunque existe cierta duda sobre la posibilidad de que se trate de una aglomeración con más densidad de hábitat.

60 R. Hodges, "The Late Roman villa”, San Vincenzo al Volturno l: excavations and surveys 1980-1986 (London, 1990).
} 
planimetría de esta nueva uilla -que ocupaba cerca de I'5 ha- condicionaron a perpetuidad la concepción arquitectónica del conjunto eclesiástico y monástico que se instala al este y cuyas iglesias están en uso en el mismo momento que la uilla. El material arqueológico ha proporcionado la cronología del abandono que se sitúa a principios del siglo $\mathrm{VI}$, aunque algunas sepulturas del cementerio denotan una presencia al menos a lo largo del siglo VI y VII. De ello se desprende que en el momento de fundación de la abadía, en el año 703, la población sería muy escasa o inexistente. Durante la primera mitad del siglo VIII, el monasterio estaba formado por una pequeña comunidad y modestas estructuras que nada tienen que ver con la grandiosidad y complejidad de todo el conjunto monástico de la segunda mitad del siglo VIII y del siglo IX.

\section{La ocupación de una uilla por una necrópolis}

La transformación parcial o total de una uilla en necrópolis, es también uno de los fenómenos atestiguado habitualmente en este tipo de hábitat, a lo largo de los siglos VI y VII, e incluso más tardíamente ${ }^{61}$. No pueden ser contemplados todos los ejemplos conocidos, pero sí se han seleccionado algunos casos donde la implantación del cementerio es muy clara pues ocupa sectores relevantes de la arquitectura residencial.

Además existen regiones particulares donde se han realizado análisis detallados para observar este fenómeno. Un ejemplo claro es el de la Normandía donde se llevó a cabo un estudio sobre la reutilización funeraria de los edificios antiguos ${ }^{62}$. A partir de unas veinte uillae, pudieron detectarse dos modelos de implantación cementerial. El primero se refiere a la ocupación de una parte de la zona residencial o bien al sector termal y el segundo ve apa- recer sepulturas en los edificios anexos, correspondientes a la pars rustica. Por regla general estas necrópolis son de época merovingia y no sobrepasan el período carolingio, y se ajustan siempre a la arquitectura preexistente, es decir siguen la alineación de los muros, aunque se desconoce en que estado estaba la construcción en aquel momento. Parece por tanto que existe una distribución clara en la organización cementerial, puesto que además no son un pequeño número de sepulturas sino que pueden llegar a rondar el centenar. Por ejemplo en la estructura termal de Gisay-la-Coudre (Beaumesnil, Eure) fueron excavadas cerca de 80 tumbas fechadas todas ellas de finales del siglo $\mathrm{VI}$ y a lo largo del siglo VII, asentadas sobre un nivel estratigráfico fruto de una destrucción del siglo III. La posible relación de este cementerio con un ámbito que pudo haber tenido la función de iglesia no se ha constatado con total fiabilidad.

En Italia septentrional se ha prestado cierta atención sobre este tipo de comportamiento, aunque sólo se citarán un par de ejemplos de diversa naturaleza. El primero de ellos es el de la uilla de Desenzano (Lago di Garda, Brescia) donde las intervenciones realizadas durante los años 1920 en los sectores A y B del edificio residencial descubrieron numerosas sepulturas $^{63}$. Las inhumaciones documentadas en el sector A, correspondiente a las habitaciones cercanas al peristilo y a la sala trichora, se sitúan sobre los pavimentos musivos o sobrepuestas a los muros y se caracterizan por una orientación N-S y la ausencia de depósitos funerarios (Fig. 8). Estos elementos, unidos a las características tipológicas de una de las tumbas (forma antropoide), lleva a los investigadores a proponer una datación dentro de la alta edad media. En el sector B, en la exedra de una gran sala pavimentada con un opus sectile, se documentó una sepultura infantil de cuidada factura y con

\footnotetext{
61 Un ejemplo de la ocupación de una uilla con fases de la antigüedad tardía por un cementerio medieval, del siglo X, se encuentra en Baños de Valdearados (Soria), cf. Arce, "Otium et negotium: the great estates, 4th-7th century", p. 31.

62 Le Maho, "La réutilisation funéraire des édifices antiques en Normandie au cours du haut Moyen-Âge", pp. I0-2I.

63 M. Bolla, "Le necrópoli delle ville romane di Desenzano e Sirmione", La fine delle ville romane, Brogiolo (ed.), pp. 5I-70, especialmente pp. 5 I-54.
} 
forma de pentágono alargado. La ubicación de la tumba (ligeramente desplazada del punto central del ábside de este ámbito) y el cuidado con que fue construida hacen pensar a los investigadores en una sepultura "privilegiada" y sugieren un posible uso cultual (oratorio privado) de este espacio, función que se fecharía entre finales del siglo IV y el $\vee$ momento en que en la sala se instala el pavimento de sectile ${ }^{64}$ (Fig. 9).

El otro caso, situado en la misma zona del Garda, responde a una serie de factores completamente diversos, se trata del gran conjunto monumental de la uilla denominada "Grotte di Catullo" en Sirmione. Las excavaciones llevadas a cabo a partir del siglo XIX, si bien revelaron la importancia de esta gran residencia de época augustea, también mitigaron la posibilidad de definir - en gran parte- las estratigrafías de los momentos finales de la ocupación ${ }^{65}$. Sin embargo, las recientes revisiones han facilitado documentación sobre la presencia de un cierto número de sepulturas -cerca de cincuenta- de mediados del siglo IV a inicios del siglo $\mathrm{V}$, con una presencia esporádica hasta el siglo VII ${ }^{66}$, correspondientes a las fases más tardías de ocupación, posteriores a la destrucción de la planta superior de la uilla puesto que se apoyan sobre grandes niveles de escombros constructivos ${ }^{67}$ (Fig. 10). El momento de destrucción y abandono del monumental conjunto arquitectónico parece que es posterior al siglo III, fecha corroborada por el hallazgo de otra uilla de menor envergadura en
Sirmione mismo (via Antiche Mura) que reutiliza en sus fases del siglo IV avanzado materiales arquitectónico-decorativos procedentes de las "Grotte di Catullo" ${ }^{68}$. Si bien el comportamiento de este gran conjunto es relativamente paradójico, se inscribe en la propia lógica de la evolución de la Península de Sirmione. Es decir, toda la Península, a partir de los siglos IV $\circ \mathrm{V}$ queda englobada dentro de un gran recinto murario con claras funciones de fortificación. De ahí se desprende que existe una reorganización poblacional en toda la zona, reservando algunos de los entonces espacios abiertos y destruidos de las "Grotte de Catu"lo" como necrópolis, por la presencia abundante de sepulturas, y cómo lugar de hábitat precario y temporal dada la aparición de pequeños hogares, a lo largo de la antigüedad tardía y la alta Edad Media, e incluso de la baja Edad Media. A partir de este momento la reorganización poblacional en una nueva concepción y planificación de Sirmione como un castrumciuitas ${ }^{69}$.

La presencia de una necrópolis o una serie de inhumaciones bien ceñidas a una o varias partes de una uilla, obliga a plantearse algunas cuestiones. Es posible suponer que la estructura arquitectónica original o aquellos sectores remodelados, continuaron en uso de una forma u otra, aún a pesar de tener la zona sepulcral cercana al lugar de hábitat. Algunos autores consideran que la presencia de sepulturas en una uilla es debida al desplazamiento del hábitat, es decir, la antigua estructura de la uilla es

\footnotetext{
64 A pesar de que los argumentos que aportan los investigadores para la identificación de este ambiente como oratorio privado son muy débiles hay que recordar el hallazgo en esta uilla de varias lucernas decoradas con motivos cristianos, de un fragmento de vidrio inciso con la figura de Cristo y el gallo y la presencia de un mosaico con una escena en la que aparece un joven rodeado por varios animales identifcada como la imagen del Buen Pastor, elementos que, eso sí, confirman la cristianización del dominus de la residencia. M. Sannazaro, La cristianizzazione delle aree rurali della Lombardia (IV-VI sec.). Testimonianze scritte e materiali (Milán, 1990), pp. 32-33.

65 E. Roffia, “Considerazioni sulle fasi più tarde delle 'Grotte di Catullo' a Sirmione”, La fine delle ville romane, Brogiolo (ed.), pp. 43-49.

66 M. Bolla, "Le necropoli delle ville romane di Desenzano e Sirmione", La fine delle ville romane, Brogiolo (ed.), pp. 5I-68. Las cronologías propuestas son bastante fiables pues muchas inhumaciones contenían en su interior materiales.

67 Las estructuras murarias del piso superior sufrieron una destrucción evidente en su elevación. Las plantas inferiores, excavadas directamente en la roca y dedicadas al servicio, se mantienen intactas tal como preveía la planificación planimétrica original.

68 Roffia, "Considerazioni sulle fasi più tarde delle 'Grotte di Catullo' a Sirmione”, pp. 44-45, advierte de la fragilidad de esta hipótesis debido a las excavaciones antiguas, pero parece que un importante incendio destruyó gran parte de la uilla.

69 Cf. G. P. Brogiolo, "Il popolamento e l'organizzazione del territorio tra età romana e alto Medioevo", Atlante del Garda. Uomini, vicende, paesi, Catalogo della mostra organizzata nel ventennale di fondazione dell'ASAR (Brescia, I99|), pp. I52-I55.
} 
abandonada y la población es transferida a otro lugar ${ }^{70}$. Si bien esto es cierto, gracias a algunos ejemplos que ya se han visto, también lo es que existe con el paso del tiempo una lenta penetración de las inhumaciones, en los ámbitos habitativos, es decir el mundo de los muertos y el mundo de los vivos se acerca cada vez más el uno al otro. Esta constatación parece que es efectiva a partir del momento, probablemente a inicios del siglo VII, en que las grandes necrópolis aisladas o en área abierta empiezan a ser abandonadas en favor de grupos cementeriales de menor entidad pero que están en relación a una iglesia, en su mayoría con funciones parroquiales. La proliferación de un modelo como éste -iglesia más cementerioen ámbito rural característico de época medieval nada tiene que ver con la situación de épocas anteriores, aunque sí que es cierto que existen abundantes ejemplos donde este tipo de modelo se constata ${ }^{71}$. Precedentemente se ha visto como la instalación de una iglesia y un cementerio puede ser contemporáneo, como es el caso de Sao Cucufate, o la iglesia es anterior a las sepulturas, como en la uilla Fortunatus, o bien las tumbas preceden a la iglesia. De cualquier forma y tal como se verá más adelante, hay que ser prudentes en las conclusiones que de ello se derivan.

\section{El abandono de una uilla y su utilización como hábitat temporal precario}

Otro tipo de reutilización es el caso de las uillae que aparentemente han sido dejadas al abandono favoreciendo la instalación de un hábitat temporal precario.
Los ejemplos de esta categoría son numerosos y sólo se apuntará uno por el contraste que se produce entre el esplendor de la uilla y el final de la misma: la uilla de Montmaurin (Haute-Garonne) cuyo origen se remonta a la segunda mitad del siglo I d.C. ${ }^{72}$ A principios del siglo II, la estructura residencial será embellecida y a finales de ese mismo siglo, una inundación destruye la pars rustica y la derecha de la pars urbana. En ese momento, gracias a la documentación arqueológica, se detecta un abandono prolongado o ausencia de actividad que perdurará hasta entrada la segunda mitad del siglo III, cuando el edificio central es acondicionado con reformas utilitarias. La uilla sufre una lujosa transformación en el primer tercio del siglo IV, pero muy poco tiempo después se produce un incendio que destruye el templo ubicado en el patio de recepción y obliga a efectuar reformas en gran parte de la uilla, aunque ya desde este momento parece sufrir un estado de empobrecimiento y semi-abandono. A finales del siglo IV se produce nuevamente otro gran incendio que parece es el que acaba con la vida de la uilla. Los últimos niveles estratigráficos han permitido documentar que las estructuras de la uilla debieron servir como lugar de hábitat, quizás temporal. Han sido hallados restos constructivos desplazados y reutilizados en el atrio y en el impluvium, así como restos de hogares en el vestíbulo de la entrada ${ }^{73}$. El proceso de transformación de esta gran uilla monumental de Montmaurin en un hábitat temporal muestra como la elección de los campamentos o hábitats temporales no dependían de un tipo o otro de estructura, sino, muy probablemente, del estado de abandono o no por parte de los propietarios.

\footnotetext{
70 Percival, The Roman Villa. An Historical Introduction, pp. 184-185.

7I Percival, The Roman Villa. An Historical Introduction, pp. 191-192, considera que por regla general la aparición de una iglesia es debida a la existencia de un templo anterior y a que las estructuras de la uilla estaban muy deterioradas. Creemos que la documentación arqueológica actual, no permite esta simplificación.

72 G. Fouet, La villa gallo-romaine de Montmaurin (Gallia, Suppl. XX, París, 1969; reed. 1984).

73 El proceso de abandono final de la uilla plantea problemas de datación, puesto que hasta el momento los mosaicos habían sido fechados por regla general a finales del siglo IV, cf. C. Balmelle, Recueil général des mosaïques de la Gaule, IV. Province d'Aquitaine, I. Partie méridionale (Piémonte pyrénéen) (Gallia, Suppl. X, París, 1980), p. 83. Aunque es muy posible que sean un poco más tardíos, de los siglos V y VI. P-A. Février, "Villes et campagnes des Gaules sous I'Empire", Ktema 6 (I98I), pp. 359-372, cf. pp. 368-37I. La misma datación le sugieren los mosaicos de Loupian, Taron, Valentine y La Hillière (que considera una uilla y no un templo), a raíz de los ciclos representados y tras la lectura de Sidonio Apolinar (Ep. 2,9; Carm. 24).
} 


\section{Traslados de hábitat dentro del ámbito de las propiedades}

Dos modelos de modificación en la ubicación del hábitat y difíciles de contrastar arqueológicamente, son los que se refieren tanto a las uillae como a los pequeños núcleos de hábitat.

Las uillae situadas en la región del Var (antigua Narbonnensis) sufren una serie de cambios en el siglo III. Algunos hábitats, como el de las uillae de la Croix du Sud y de Pardigon 1/3 desplazan su población a Cavalaire (éste dudoso) y Pardigon 2, respectivamente. Un fenómeno similar ocurre en Saint-Pierre (Eyguières, Bouches-du Rhône), donde la uilla ocupada entre los siglos I a.C. y III d.C. (Saint-Pierre II) es abandonada en favor de una construcción de nueva planta. Ésta última, Saint-Pierre I, puede ser fechada a finales del siglo III teniendo continuidad hasta el siglo $X$. Este comportamiento es posible que responda a una necesidad en la agrupación de las explotaciones y de los medios de producción ${ }^{74}$.

El segundo modelo que parece se empieza a documentar es el referido al traslado de pequeños núcleos urbanos a otras zonas relativamente cercanas. Si bien se hace difícil encontrar las razones que expliquen este tipo de traslado, puesto que la posible existencia de un cambio en el sistema de explotación no parece una argumentación suficientemente sólida. Los motivos, si realmente los traslados son ciertos, debieron responder a más de un factor. El caso de Lunel (Hérault) podría pertenecer a esta categoría puesto que entre el siglo IV y el siglo $\mathrm{VI}$, se detectan variaciones en la localización del hábitat privilegiando unas zonas sobre otras ${ }^{75}$.

\section{La uilla como origen de una aglomeración medieval}

Las minuciosas excavaciones llevadas a cabo en grandes extensiones del valle alto del Ródano, han proporcionado una evidencia que resulta de gran interés: la mayoría de aglomeraciones medievales se hallan situadas en lugares donde con anterioridad había existido una villa ${ }^{76}$. Esta continuidad entre el yacimiento romano y el núcleo medieval no se ve interrumpida, ni tan siquiera por la llegada de nuevas poblaciones "bárbaras", aunque es posible apreciar cómo desde la segunda mitad del siglo III se produce un proceso de transformación que afecta a la pars urbana. Su organización se ve simplificada, aunque el dominus sigue estando presente ${ }^{77}, y$ el hábitat se dispersa alrededor del núcleo de la uilla, apareciendo también grandes necrópolis, cuyas sepulturas, por regla general, han podido ser fechadas entre los siglos $V$ y IX.

Tanto en Italia, como en la Gallia existe un tipo de uilla, la fortificada o con torres de vigilancia, que puede dar lugar a un castrum o un burgo medieval. Se ha mencionado el caso de las "Grotte de Catullo" que durante la alta Edad Media queda integrado dentro de lo que es el castrum de Sirmione. En la Gallia este tipo de construcciones, uillae fortificadas, se ha documentado más o menos de una forma general, incluyendo la Gallia meridional ${ }^{78}$. Claros ejemplos de este tipo de protección, es decir la construcción de torres de vigilancia o defensa, se hallan en la uilla de Odrang en Renania; y en Sisteron (Alpes Marítimos), gracias a una inscripción se sabe que Claudius Postumus Dardanus, prefecto del pretorio de la Gallia, hizo proteger con una estructura muraria su propiedad de nombre Theopolis construyendo así una fortaleza ${ }^{79}$.

\footnotetext{
74 Pellecuer, "Villa et domaine", pp. 282 y 288-289, fig. 5.

75 Ph. Leveau, P. Sillières y J.-P. Vallat, Campagnes de la Mediteranée romaine. Occident (París, 1993), p. 262.

76 Uno de los primeros investigadores en documentar este fenómeno, gracias al estudio de la fotografía aérea, fue R. Agache, "La campagne à l'époque romaine dans les grandes plaines du nord de la France", Aufstieg und Niedergang der Römischen Welt, 2,4 (Berlín-Nueva York, 1975) pp. 658-7I3. Para el valle del Ródano ver Bonnet, "Les églises rurales de la région de Genève", pp. $22-35$.

77 La afirmación viene de Bonnet, "Les églises rurales de la région de Genève", p. 22.

78 Le Glay, “La Gaule romanisée”, p. 282.

79 Salway, Roman Britain, pp. 452-453, donde además se argumenta la problemática de las uillae o propiedades fortificadas.
} 
Este tipo de uilla fortificada se perpetuará en época medieval, puesto que la fortificación de las propiedades privadas rurales empieza a ser una práctica común -al menos en la Galliaa partir de la segunda mitad del siglo IX. Se tiende a establecer una relación entre este tipo de fortificación con la de las ciudades, indicando ambos casos y de forma simbólica el poder sobre el territorio ${ }^{80}$.

\section{La necrópolis de una uilla reocupada con posterioridad}

Si bien ya se ha visto que los diferentes tipos de transformación y final de las uillae es muy variado y en algunos casos se observa con claridad el porqué del proceso, también cabe señalar el caso -muy poco frecuente- de la necrópolis de una uilla reocupada con posterioridad. Las excavaciones llevadas a cabo en Barrow Hills y Barton Court Farm (Oxfordshire) revelaron la existencia de dos hábitats rurales, con una ocupación anglosajona que se inicia en la primera mitad del siglo $\bigvee^{81}$. Ambos núcleos se hallan separados por un curso de agua y a $500 \mathrm{~m}$ de distancia, aunque eran interdependientes y funcionaron conjuntamente. Barton Court Farm corresponde al emplazamiento de una uilla abandonada en el primer cuarto del siglo $\mathrm{V}$, que fue reocupado con siete cabañas, ocho edificios con postes de madera, un pozo y cuatro sepulturas, comportamiento habitual en lo hasta ahora se conoce de las transformaciones y continuidad de las uillae. Menos frecuente es lo que sucede en Barrow Hills, donde al parecer la ocupación anglosajona se inicia hacia el año 450 y perdurará hasta entrado el siglo VII (Fig. II). Inicialmente el lugar estuvo ocupado, además de por monumentos de época neolítica y de la Edad del Bronce, por el cementerio dependiente de la uilla. Sin embargo la instalación anglosajona preservó siempre la zona de la necrópolis y las nuevas construcciones -se han documentado cerca de veintidós edificios-y el nuevo cementerio, no invadieron en ningún momento dicho área sepulcral.

A pesar de la simplificación que se ha intentado establecer a través de las diferentes categorías, el proceso de transformación de las estructuras residenciales no debió ser tan simple como puede aparentar. De cualquier forma se debe hacer hincapié en que tanto las categorías establecidas como los ejemplos aducidos son el resultado de un primer bosquejo. Diversos factores -esencialmente religiosos, económicos y culturales- que se intentarán dilucidar más adelante, intervinieron en la modificación estructural y funcional de la uilla romana clásica.

\section{PROBLEMAS DE CRONOLOGÍA Y FACTORES QUE INTERVIENEN EN EL PROCESO DE TRANSFORMACIÓN}

Establecer en qué momento se producen estas modificaciones y sobre todo cuándo finaliza el hábitat -de un tipo u otro- en las estructuras residenciales y en los establecimientos rurales -e indirectamente en las áreas urbanassólo puede realizarse a partir de un análisis pormenorizado del material arqueológico procedente de cada yacimiento. Si bien esa no es la intención inicial de este estudio, sí que se observan algunos comportamientos que permiten ofrecer una primera hipótesis de trabajo.

Es muy posible que el cambio en el uso de las estructuras residenciales ocurra en los siglos $\checkmark y \mathrm{VI}$. Sin embargo en algunos casos, tal como se ha podido constatar en Hispania y la Gallia, parece que la transformación principal se documenta ya en los siglos III y IV ${ }^{82}$. Algunos auto-

80 M. Fixot, "Une image idéale, une réalité difficile: les villes du VIle au IXe siècle", La ville antique, des origines au IXe siècle, G. Duby (ed.), Histoire de la France urbaine, P.-A. Février, M. Fixot, Ch. Goudineau y V. Kruta (París, 1980), pp. 497-563, cf. p. 509.

81 La información ha sido extraída del artículo de carácter general de A. Dodd y E. McAdam, "L'habitat rural en Anglaterre durant la période anglo-saxonne", L'habitat rural du haut Moyen-Âge (France, Pays-Bas, Danemark et Grande-Bretagne), C. Lorren y P. Périn (eds.) (Rouen, 1995), pp. 223-234, cf. pp. 228-229.

82 Leveau, Sillières y Vallat, Campagnes de la Méditerranée romaine. Occident, pp. 215-224, consideran incluso que el abandono de muchas uillae se produce en los siglos II y III, p. 269. 
res consideran que esta primera fase (siglos III y IV) de las transformaciones en una estructura residencial son debidas a una crisis agrícola de carácter general que debe ser puesta en relación directa con las modificaciones en la producción y elaboración de determinados productos y por tanto con la disgregación de los grandes circuitos comerciales a la vez que la activación de redes locales con centros múltiples de producción y comercialización ${ }^{83}$. Sin embargo, existen casos paradigmáticos como es el de las uillae de Campania que en su mayoría habían pertenecido a emperadores y grandes propietarios de la clase senatorial. Se trata de lugares de residencia ocupados, por regla general, desde el siglo I a.C. hasta el siglo III. Sólo nueve uillae tienen una continuidad hasta el siglo IV y en tan sólo cuatro de éstas se ha documentado cerámica del siglo VI ${ }^{84}$. En el caso de Posto (Capua, Campania) por ejemplo, la uilla fue ocupada por "squatters" desde finales del siglo IV hasta el siglo V| ${ }^{85}$. Este hecho es particularmente relevante y por ello se debería realizar un estudio preciso sobre el final de este tipo de uillae, puesto que es bien conocida la práctica realizada por parte de los emperadores a partir del siglo IV, de donar propiedades o tierras a la Iglesia ${ }^{86}$.

Un comportamiento similar, aunque por motivos distintos se documenta en las uillae de la zona del Garda ${ }^{87}$. Todas aquellas que se sitúan en primera línea del lago o sobre el promontorio de Sirmione no comportan desde su fundación estructuras productivas, sin embar- go aquellas situadas en el hinterland, lo que en esta región es la primera línea de colinas, además de la zona residencial, tienen un sector dedicado a la explotación agrícola. Las transformaciones que se observan en estas grandes uillae residenciales no afectan por tanto a la funcionalidad propia del conjunto monumental, sino que sufren un periodo de abandono para luego ser utilizadas esporádicamente como lugar de enterramiento, tal es el caso de la mencionada "Grotte di Catullo" en Sirmione.

El problema del autoabastecimiento, basado en una economía de autosuficiencia, es la explicación que en muchos casos se ha dado para comprender, por un lado las transformaciones de las uillae de la antigüedad tardía y por otro el surgimiento de nuevos modos de hábitat ${ }^{88}$. Si bien es una interpretación que ha sido muy utilizada y que no deja de tener coherencia, actualmente el estudio de los materiales arqueológicos y esencialmente la continuidad en las importaciones cerámicas ${ }^{89}$, al menos hasta finales del siglo VII, tanto occidentales como orientales, hace que la problemática suscitada por el autoabastecimiento esté en proceso de revisión.

Algunos investigadores vinculan las transformaciones de las uillae al período de las primeras incursiones bárbaras, cuya presencia ha sido siempre considerada como catastrófica -un "mal endémico"- tanto por los autores contemporáneos como en la actualidad ${ }^{90}$. Este tipo de constataciones se apoya en una docu-

\footnotetext{
83 Ortalli, "La fine delle ville romane: esperienze locali e problemi generali", p. I3.

84 Sodini, "Habitat de l'Antiquité tardive", p. 173, a partir de la información proporcionada por P. Arthur, Romans in northern Campania (Londres, 1991).

85 Aunque hay que tener en cuenta que entre los años 160 y 370, existen reformas de muros y un abandono en la zona norte y en las cisternas, cf. Leveau, Sillières y Vallat, Campagnes de la Méditerranée romaine. Occident, pp. I37 y I39.

86 R. MacMullen, "Two notes on imperial properties", Athenaeum 54 (1976), pp. 19-36.

87 Brogiolo, "Il popolamento e l'organizzazione del territorio tra età romana e alto Medioevo", pp. I43-I65.

88 G. Webster, "The Future of Villa Studies", The Roman Villa in Britain, A. L. F. Rivet (ed.) (Londres, 1969), pp. 217-249, cf. p. 231.

89 C. Panella, "Merci e scambi nel Mediterraneo tardoantico", Storia di Roma, 3, L'età tardoantica, 2, I luoghi e le culture (Turín, I993), pp. 613-697. Véase el caso puntual pero esclarecedor de África en: D. Manacorda, "Nador (Tipasa, Algeria). II contesto della villa di M. Cincius Hilarinus", Società romana e impero tardoantico, A. Giardina (ed.), 3, Le merci. Gli insediamenti (Roma-Bari, 1986), pp. 203-208 y $818-819$

90 Esta afirmación se constata de una forma global en la bibliografía actual, al menos hasta finales de los años 1980 (cf. Le Glay, "La Gaule romanisée", pp. 279-285, como revisión general de este problema en la Gallia), aunque en la actualidad se tiende hacia nuevas interpretaciones.
} 
mentación arqueológica escasa y de difícil interpretación. Es decir, niveles de incendio o estratos con carbones y cenizas han sido siempre identificados con momentos de devastación, hecho que no puede ser generalizado, y menos aún relacionado de forma sistemática con la presencia de nuevas poblaciones. En Britannia desde finales de los años 60 se determinó que la presencia de pueblos bárbaros y sus devastaciones, no podían en ningún caso documentarse arqueológicamente y servir como elemento de datación para el final de las uillae o de los establecimientos, puesto que además existían claros indicios para defender la continuidad sin rupturas ${ }^{91}$. Sin embargo, esta continuidad se hace patente a nivel rural pero no por el momento a nivel urbano ${ }^{92}$. Por otra parte, las interpretaciones en relación a la presencia de bárbaros, son también las que se han propuesto prácticamente siempre en cuanto al paisaje urbano, la construcción o restauración de recintos fortificados, el abandono de determinados sectores urbanos, etc. Aunque hoy en día se detectan otro tipo de posibles interpretaciones a nivel histórico, cultural y social, más en relación con una nueva imagen de la ciudad y un nuevo sistema de articulación urbana que con las devastaciones producidas supuestamente por los bárbaros ${ }^{93}$.

La documentación literaria ayuda, por su parte, a resolver algunos problemas e interrogantes, aunque su misma naturaleza retórica y escolástica reclama precaución y prudencia en la interpretación. Pondremos algunos ejemplos. La Chronica de Prospero Tironense nos informa de que en el 419 el patricio Constancio con- cedió a los visigodos la Aquitania Secunda para que se establecieran en ella, incluyendo como puntos de asentamiento las ciudades, $\mathrm{O}$, al menos, algunas ciudades: data ei (Wallia) ad inhabitandum secunda Aquitanica et quibusdam ciuitatibuss confinium provinciarum ${ }^{94}$. De este texto se deduce claramente que los visigodos no se establecieron sólo en tierras no pobladas o en uillae que eran antiguos asentamientos o propiedades romanas (uillae) dispersas por el territorio, sino que se les permitió también ocupar ciudades (no todas ni cualesquiera, sino algunas de los confines de la provincia). Conclusión semejante parece deducirse del texto de Hydacio (Chr. 4l.49) en donde dice que los hispanos habitantes en ciuitates et castella (es decir, en ciudades y en uillae) se sometieron a los suevos, vándalos y alános a partir del 410. El control de las ciuitates y la presencia de bárbaros en las mismas está implícito en el texto.

Existen ejemplos arqueológicos de la continuidad de las uillae, a pesar de la presencia de nuevas poblaciones e incluso instalándose sobre las estructuras arquitectónicas. Se ha hecho mención precedentemente de una franca de nombre Irmina que fundó un monasterio en Echternach, sin embargo un caso paradigmático es el de la uilla de Mienne-Marboué (Châteaudun, Eure-et-Loire) en la zona occidental de la antigua Lugdunensis. La uilla con las características estructuras de este tipo de establecimiento ${ }^{95}$, fue ocupada a finales del siglo $\checkmark$ por un franco (?) de nombre Steleco, tal como consta en el mosaico situado frente a la entrada principal de los espacios de recepción donde se lee: EX OFFICINA FERRONI FELIX VTI

\footnotetext{
91 Webster, "The future of Villa Studies", pp. 217-249.

92 Painter, "Villas y Christianity in Roman Britain", p. 158.

93 Es a partir de los trabajos de P.-A. Février que esta nueva imagen de la ciudad se empieza a tener en consideración, cf. a modo de síntesis general Février, Fixot, Goudineau y Kruta, La ville antique, des origines au IXe siècle, pp. 399-493. De aparición más reciente G. Cantino Wataghin, "Urbs e civitas nella tarda antichità: linee de recerca", P. Demeglio y C. Lambert (eds.), La 'civitas christiana'. Urbanistica delle citta italiane fra tarda antichità e altomedioevo (Turín, 1992), pp. 7-42. Una revisión firme sobre la denominada "barbarización" del paisaje es la de G. Traina, "Paesaggi tardoantichi: alcuni problemi", La storia dell'alto Medioevo italiano (VI-X secolo) alla luce dell'archeologia, R. Francovich y G. Noyé (eds.), (Biblioteca di Archeologia Medievale II, Florencia, 1994), pp. 85-98.

94 Chron. 419, Th. Mommsen (ed.), MGH, AA, Chr. Min., p. 469.

95 Lo esencial de la información ha sido reunido por M. Blanchard-Lemée, "Mosaïques tardives et survie des villas en Gaule moyenne a l'èpoque mérovingienne", Mosaïque. Recueil d'hommages a Henri Stern (París, 1983), pp. 75-80, cf. pp. 76-78. Algunas notas complementarias y el estudio de los mosaicos en: Ead., Recueil général des mosaïques de la Gaule, Province de Lyonnaise. 4. Partie occidentale, (Gallia, Suppl. X, II, París, I99I), pp. 25-32.
} 
STELECO (Fig. 12). Los capiteles merovingios hallados documentan una segunda fase de reestructuración de la uilla en el siglo VII. La ocupación de la uilla, tiene constatada una utilización de la parte residencial que va desde finales del siglo V hasta entrado el siglo VII. En la pars rustica, las antiguas excavaciones pusieron al descubierto una necrópolis merovingia con tumbas de jefes francos y una cronología igual (siglos V al VII). La construcción de un lugar de culto cristiano originó la posterior iglesia construida en el siglo XII y la aglomeración medieval, apoyándose sobre una de las estructuras murarias de la pars rustica. El ejemplo de Mienne-Marboué muestra no sólo una continuidad y una serie de transformaciones estructurales y funcionales, sino que se trata también de un caso significativo de ocupación por parte de una familia noble franca de una uilla típica romana que había pertenecido a otro propietario. Sin embargo, y sólo por el momento, el final de la uilla y del establecimiento rural parece que se sitúa hacia finales del siglo VII dado que siguen llegando importaciones cerámicas con estas cronologías, aunque algunos investigadores consideran ya los siglos $\mathrm{V}$ y $\mathrm{VI}$ como una fase terminal ${ }^{96}$.

En África, la plasmación arqueológica del mundo rural es muy escasa ${ }^{97}$, sin embargo el conocimiento de las explotaciones agrícolas es por vía indirecta. La epigrafía, la prosopografía, los textos y las representaciones musivas son los útiles para reconstruir la evolución y el final de las elites urbanas y rurales. Procopio cuando se refiere al establecimiento de los vándalos en África. En efecto, Procopio ofrece tres ejemplos muy significativos acerca de cuál o cuáles fueron las actitudes de los bárbaros ante las uillae del norte de África cuando se instalaron en el territorio. En un pasaje en el que habla del rey Genserico, dice "que sometió a todos los propietarios de las uillae de Libia a la esclavitud, confiscando sus tierras y su rique- za". Y continúa: "Por lo que se refiere al resto de los libios, les robó sus posesiones, que eran numerosas y magníficas, y las distribuyó entre la natio de los vándalos. Como resultado de ello, estas tierras se han llamado 'las posesiones de los vándalos' todavía hasta nuestros días. Y cayó sobre quienes habían tenido estas tierras el tener que vivir en extrema pobreza. Pero por lo que se refiere a la tierra que consideró poco rentable, permitió que quedase en manos de sus antiguos propietarios, pero les obligó a pagar una tal cantidad de tasas al gobierno que no quedaba nada a quienes pudieron retener sus tierras" (BV I,5, I I).

En otro pasaje del mismo historiador encontramos, sin embargo, al rey de los vándalos viviendo en una magnífica uilla a pocos kilómetros de la capital, Cartago, disfrutando del cultivo de jardines y huertos (BV I, I 7,8). Y, finalmente, el historiador describe tambien (BV $\|, 6,9)$ cómo los vándalos hacían uso de las termas romanas -lo que implica la reparación o mantenimiento del acueducto-, celebrando siempre espléndidos banquetes en sus triclinia o salas de recepción, vestidos con ricas ropas recamadas en oro "de verdadero estilo persa", deleitándose en teatros y en los hipódromos y, sobre todo, dedicándose al arte de la caza. "Muchos de ellos -termina Procopio- vivían en los parques que estaban magníficamente surtidos de aguas y árboles, y celebraban numerosos banquetes y toda clase de placeres sexuales estaban en boga entre ellos". Son estos, tres modos de presentar la ocupación del territorio por parte de los pueblos bárbaros. Si en ello hay una visión interesada de la realidad -hecho posible- el fondo puede considerarse esencialmente verídica, aunque parcial, porque, sin duda, hubo otros muchos y diversos comportamientos en las formas de establecimiento.

En resumen, Procopio nos habla de tres tipos de ocupación: I) confiscación de propie-

\footnotetext{
96 Ortalli, “La fine delle ville romane: esperienze locali e problemi generali”, p. I5.

97 Entre los pocos estudios existentes dedicados al análisis del territorio, de los establecimientos rurales y las uillae en África recordamos el ya clásico de P. Leveau, Caesarea de Mauretanie, une ville romaine et ses campagnes (Roma, 1984) o el estudio de R. Bruce Hitchner, "The Organization of Rural Settlement in the Cillium-Thelepete Region (Kasserine, Central Tunisia)", L'Africa Romana, Atti del VI convegno di studio Sassari, I6-I 8 dicembre 1981, A. Mastino (ed.), (Sassari, 1989), pp. 387-402.
} 
dades agrícolas -que eran muchas y excelentes- y distribución entre los vándalos de las mismas. Consiguientemente, cambio de denominación de estas posesiones: en vez de "constantiniana" o "filosofiana" etc., ahora "tierras vandálicas"; 2) empobrecimiento de los propietarios romanos; 3) las tierras que parecían poco rentables quedaban en manos de sus propietarios que, sin embargo, tenían la obligación de pagar tales tasas, que prácticamente no restaba nada a sus antiguos dueños. La segunda fórmula sería: ocupación de las uillae por el rey y la aristocracia vándala, aprovechando de sus ventajas. En esta segunda forma no habría habido mas que una sustitución del propietario. La tercera, casi idéntica a la anterior, sería: los vándalos acaban viviendo a la manera romana, utilizando termas, circos, teatros y triclinia.

¿Es este, o son estos, los modos de utilización de las uillae en todas partes donde se asentaron bárbaros? Es cierto que el caso vándalo en África es el resultado de una conquista y no de un pacto con los romanos. Pero aun así, es lícito pensar que estas fueron modalidades de ocupación, junto con otras, en todas partes.

Ahora bien, esta ocupación está poco atestiguada en el registro arqueológico y no se sabe si implicó la continuidad de la explotación económica del fundus (hay indicaciones en el propio Procopio de que ello no fue así). Parece por tanto que los vándalos se limitaron a usufructuar los espacios y vivieron de la renta de los dominados ${ }^{98}$.
Otro de los temas sugestivos todavía por profundizar, es el de saber que hicieron los musulmanes con este tipo de explotación o de uillae a lo largo y ancho de, por ejemplo, Siria, Egipto, norte de África e Hispania. ¿Se identifican o no se identifican en absoluto con este tipo de hábitat? Es muy probable que el gran complejo arquitectónico de Cercadilla (Córdoba) que ha sido reconocido como un palacio imperial de finales del siglo IV y reutilizado hasta muy a finales del siglo VII e incluso con posterioridad ${ }^{99}$, cuando sea estudiado en su totalidad, pueda responder a esta pregunta.

El análisis de los posibles y diferentes motivos que intervienen en el proceso de transformación de las uillae y establecimientos rurales resulta complejo y afecta a diversos temas.

Varios factores interesantes deben ser recalcados para comprender el porqué de las transformaciones de las uillae e incluso su desaparición como sistema de explotación. Entre ellos destaca la cristianización de los grandes propietarios 100 y la cada vez mayor fuerza de la Iglesia. Los possessores fueron donando sus tierras a la Iglesia, en un claro acto de evergetismo ${ }^{101}$. Este último produjo una evidente transformación del sistema de hábitat y un engrandecimiento gradual, pero muy importante, del patrimonio eclesiástico. De hecho el paso de manos de un propietario a otro, en este caso a la Iglesia, provoca la conversión de algunas uillae en iglesias o en monasterios, tal como se ha visto en los ejemplos anterior-

98 Véase J. J. Rossiter, "Villas vandales: le suburbium de Carthage au debut du Vè siècle de notre ère", IV Coloque International d'Histoire et Archéologie de l'Afrique du Nord. Carthage et son territoire dans l'Antiquité, Strasbourg 5-9 avril 1988, (París, 1990), pp. 221227. Para el período inmediatamente posterior y la problemática fiscal resulta interesante J. Durliat, "Les grands propietaires africains et l'Etat byzantin (533-709), Les Cahiers de Tunisie XXIX, I I7-II8 (1981), pp. 517-531.

99 R. Hidalgo Prieto, Espacio público y espacio privado en el conjunto palatino de Cercadilla (Córdoba): El aula central y las termas (SeviIla, 1996). En contra de la identificación de esta uilla como palacio, cf. Arce "Emperadores, palacios y uillae", Antiquité tardive 5 (1997), pp. 293-302.

100 Sobre esta problemática, cf. P. Brown, "Aspects of the Christianization of the Roman aristocracy", Journal of Roman Studies 51 (196I), pp. I-II. Para el caso hispánico resulta interesante: S. Fernández-Ardanaz, "Cristianizzazione e cambiamenti sociali nelle culture montane del Nord dell'Hispania", Cristianesimo e specificità regionali nel Mediterraneo latino (sec. IV-VI), XXII Incontro dell'Antichità Cristiana, Roma, 1993, Studia Ephemeridis Augustinianum 46 (Roma, 1994), pp. 483-512.

101 Sobre el evergetismo durante la antigüedad tardía resultan importantes los artículos presentados en las preactas del $X^{*}$ Congrès International d'Épigraphie grecque et latine, Nîmes 1992: Cl. Lepelley, "Évergétisme et épigraphie dans l'antiquité tardive: les provinces de Langue latine", pp. 99-108; Ch. Roueché, "Benefactors in Late Antiquity: the Eastern Roman Empire", pp. I09-I I6; Y. Duval y L. Pietri, "Évergétisme et épigraphie dans l'Occident chrétien (IVe-Vle s.)", pp. I 17-I 40. 
mente aducidos. Esta transferencia de bienes vino favorecida también por la preexistencia de muchas uillae dotadas de oratorios privados, lo que significa que en ámbito rural existían numerosos edificios religiosos dispersos ${ }^{102}$.

Existen innumerables casos que pueden ser apuntados y por ello sólo se ofrece una pequeña muestra que nos ha parecido interesante en relación a los diferentes problemas que aquí se tratan ${ }^{103}$. Ya sólo en Roma, la información que existe sobre la práctica del evergetismo cristiano, confirma la importancia de éste para conocer la evolución de las propiedades públicas o privadas en su paso de la antigüedad tardía a la Edad Media. Se ha hecho mención ya de que a partir del siglo IV la Iglesia se enriquece gracias a las múltiples donaciones imperiales, sobre todo con las de Constantino. Los datos recogidos en el Liber Pontificalis muestran varios ejemplos de estas donaciones, esencialmente urbanas, pero también rurales. La aristocracia romana tomará el relevo de esta práctica desde finales del siglo IV hasta la segunda mitad del siglo V. El gran poder que va adquiriendo la Iglesia al engrandecer su patrimonio y tener un absoluto control papal sobre las donaciones hizo que la aristocracia viera a esta institución como un rival ${ }^{104}$. De ahí deriva una nueva forma de evergetismo que consiste en la fundación progresiva de iglesias y monasterios en las grandes propiedades rurales por parte de la aristocracia, con el fin de establecer un mayor control y como muestra de ascetismo. Varios ejemplos de este tipo están tes- timoniados en las fuentes. Así se constata que Silenius, uir honorabilis, fundó una iglesia in re Viriana iuris suis, tal como anotó el papa Gelasio (492-496) (Ep. 34). Igualmente el Liber Pontificalis (I, p. 263) recuerda la fundación de una basilica in fundum Pacinianum, por parte de Albino (praefectus praetorium) y Glaphyra. También Basilius Venantius (Decius) (Gregorio, Dial. I. I), cónsul en el año 508, fue fundador de un conjunto monástico en su propiedad de Fondi (Campania), donde el colono Honoratus pasa a ser el abad ${ }^{105}$.

Otro caso importante y significativo es el de una de las grandes familias aristocráticas romanas. Melania la Joven, perteneciente a una familia que poseía una gran cantidad de tierras dispersas por todo el Imperio, desde Hispania, Campania, Sicilia, África, Mauritania, Britannia, etc.: per orbem Romanum universum paene patrimonia sparsa possedit ${ }^{106}$. Cuando decide retirarse a la vida ascética dona su patrimonio a la Iglesia 107. El caso de Melania no es mas que uno de los muchos que se constatan después y que son bien conocidos. Entre la aristocracia ravenaica de mediados de los siglos $\mathrm{V}$ y $\mathrm{Vl}$, destaca una dama de nombre Ranilo perteneciente a una familia arriana de ascendencia goda. Con la intención de sellar su conversión, donó, además de una importante suma de dinero, la mitad de dos massae, una cerca de Urbino y otra en Lucca ${ }^{108 .}$

Al igual que en otras zonas del Imperio, también en África a lo largo del siglo IV importan-

102 A. A. Settia, "Pieve e cappelle nella dinamica del popolamento rurale", Cristianizzazione ecclesiastica delle campagne nell'alto medioevo: espansione e resistenze, XXVIII Settimane di Studio del Centro Italiano di Studi sull'Alto Medioevo (Spoleto, 1982), pp. 445-493, cf. p. 469.

103 Si bien no existe ninguna síntesis útil respecto a este problema, sí se puede recurrir a una bibliografía específica para cada caso.

104 Sobre el evergetismo en Roma, es necesario consultar la abundante información proporcionada por Ch. Pietri, "Évergétisme et richesses ecclésiastiques dans l'Italie du IVe à la fin du Ve siècle: l'exemple romain", Ktema 3 ( I978), pp. 317-337, cf. pp. 32I-326.

105 Estos ejemplos han sido extraídos de Ch. Pietri, "Aristocratie et societé cléricale dans l'Italie chrétienne au temps d'Odoacre et de Théodoric", Mélanges de l'École Française de Rome 93 (I98I), pp. 417-467, cf. pp. 426-430.

106 Vita S. Melaniae lunioris (L), i. I5, Vie grecque, 19-20, D. Gorce (ed.), SC 90, pp. 163-I7I. Véase también: M. T. W. Arnheim, The senatorial Aristocracy in the Later Roman Empire (Oxford, 1972), pp. I44- I 45.

107 Arce, "Otium et negotium: the great estates, 4th-7th century", p. 22.

108 Ch. Pietri, “Les aristocraties de Ravenne”, Studi Rogmanoli XXXIV (I983), pp. 643-673, cf. p. 67I. A partir del papiro núm. I3 (protocolo fechado en el 553) estudiado por J.O. Tjäder, Die nichtliterarischen lateinischen Papyri Romani Regni Italiens aus der Zeit 445760, I (Acta Inst. Romani Regni Sueae XIX, I, Lund, 1955) y 2 (Acta, XIX, 2, Estocolmo, 1982). 
tes familias propietarias de grandes extensiones de explotación agrícola reafirman su poder al acceder a la magistratura o a cargos militares. Un caso conocido es el de la familia de Flavius Nubel ${ }^{109}$, propietaria de muchas tierras cultivables en toda la Kabilia y que construyó, con su pecunio, una iglesia para albergar una reliquia de la Santa Cruz en Rusguniae, aunque no es posible establecer una identificación entre esta iglesia, conocida por una inscripción, y la que fue excavada muy a principios de siglo ${ }^{110}$. Se trata tan sólo de un ejemplo, aunque existen numerosos que muestran, también en África y a partir sobre todo del siglo VI, el cada vez mayor patrimonio de la Iglesia gracias a las donaciones o fundaciones privadas, siendo el obispo el máximo responsable en la supervisión y control de los impuestos y beneficios obtenidos 11 .

También en las Vitas Sanctorum Patrum Emeretensium se atestigua este mismo fenómeno ${ }^{1 / 2}$.

La existencia de una serie de testamentos confirma de nuevo la práctica habitual por parte de algunos propietarios, tanto de familias senatoriales, como aristocráticas o de menor rango social, de donar sus bienes y tierras a la Iglesia. No sólo se trata de laicos cristianos o practicantes de la vida ascética, sino también de familias eclesiásticas que donan sus herencias familiares a la Iglesia 113 .
Con anterioridad y al tratar las transformaciones de uillae en iglesias y monasterios, se ha traído a colación el caso de la uilla de Primuliacum que había pertenecido a Sulpicio Severo. Este hecho además de ser una clara muestra de evergetismo por parte de un gran propietario rural, plantea la relación entre una iglesia, en principio, de carácter privado, con una parroquia, por la aparición del baptisterio. De ahí la problemática que se establece más tardíamente en la relación villa, ecclesia y parrochia, siendo todas estas construcciones las que están vertebrando la vida religiosa de los zonas rurales y que a su vez están condicionando el paisaje rural de época medieval, tal como ya se ha indicado precedentemente.

La posibilidad de transformación y continuidad entre una uilla, un oratorium y una ecclesia, que a partir del siglo VI se convertirá -en muchos casos- en parroquia, es muy sugerente, pero no deja de ser una hipótesis, puesto que la terminología empleada se presta a la confusión ${ }^{114}$. Si bien es evidente que la estructura parroquial es uno de los pilares básicos de la Iglesia en el ámbito de la vida rural ${ }^{115}$, también es cierto que dependiendo de las coordenadas espacio y tiempo, esta estructura es efectiva o no. De cualquier forma puede establecerse una relación directa entre la existencia de las primeras parroquias con los grandes

109 G. Camps, “De Masuna à Koceila. Les destinées de la Maurétanie aux Vle et Vlle siècles”, Bulletin archéologique du Comité des Travaux Historiques et Scientifiques 19, 1983 (1985), pp. 35I-353, cf. p. 309.

110 N. Duval, “Les Byzantins à Rusguniae. Études d'archéologie chrétienne nord-africaine - X”, Bulletin archéologique du Comité des Travaux Historiques et Scientifiques 19, 1983 (1985), pp. 34I-359, cf. pp. 357-358. A. Chastagnol, en la discusión de la p. 360, propone fechar la inscripción de Flavius Nubel entre los años 400 y 429 aproximadamente. Véase también Y. Duval, Loca sanctorum Africae (Roma, 1982), pp. 35I-353, núm. 167.

III J. Durliat, "Les finances municipales africaines de Constantin aux Aghlabides", Bulletin archéologique du Comité des Travaux Historiques et Scientifiques 19, 1983 (1985), pp. 377-386, cf. p. 38I. Duval, Loca sanctorum Africae, pp. 36, 54-69, 162-164, 572-574.

112 J. Arce, "The City of Merida (Emerita) in the Vitas Patrum Emeritensium (Vlth Century A.D.)", E. Chrysos y I. Wood (eds.), East and West: Modes of Communication, Brill (Leiden, 1999) pp. I-I4.

113 Un ejemplo interesante en P. C. Díaz, "El testamento de Vicente: propietarios y dependientes en la Hispania del s. VI", Romanización y Reconquista en la Península Ibérica (Studia Historica-Historia Antigua, Salamanca, 1998), pp. 257-270.

II4 Un amplio análisis sobre el problema de la aparición y evolución de las parrochiae en la Península en G. Ripoll e I. Velázquez, "Origen y desarrollo de las parrochiae en la Hispania de la Antigüedad tardía", P. Pergola (ed.), Alle origini della parrocchia rurale (IV-VIII sec.), Atti della giornata tematica dei Seminari di Archeologia Cristiana, École Française de Rome, 19 marzo 1998 (Roma, 1999 ), pp. I01-165. Véase todo el volumen para esta problemática en diferentes zonas, aunque nosotros no hemos podido manejarlo para la redacción de este texto.

II5 M. Colardelle, "Les paroisses rurales", Naissance des Arts Chrétiennes, N. Duval (ed.) (París, 199I), pp. I22-I33. Véase también F. Monfrin, "La christianisation de l'espace et du temps. Établissement matériel de l'ëglise aux Ve et Vle siècles". L. Pietri (ed.), Histoire du Christianisme des origines à nos jours, 3, Les églises d'Orient et d'Occident (París, 1998), pp.959-1014, cf. pp. 986-I00I. 
propietarios que a través de la construcción de oratorios o iglesias privadas facilitó la implantación de esta estructura religiosa rural basada en las parrochiae 116. La utilización del término parrochia, que originalmente significa la comunidad de fieles, a partir del siglo IV debe ser entendida como una circunscripción episcopal o bien como una dioecesis, aunque no será hasta el siglo $\mathrm{Vl}$ y a pesar de toda una serie de problemas semánticos que parrochia puede ser definida como tal. La evolución de la palabra uilla a lo largo de la alta Edad Media hace que en muchos documentos de plena época medieval, o al menos en los entornos del año mil, conduzcan a la correspondencia o pareja identificación entre una uilla y una parrochia ${ }^{17}$.

Otro elemento fundamental para comprender las transformaciones aquí estudiadas se refiere a posibles factores concernientes a la existencia o no de una redistribución de la riqueza 118. Algunos estudios han permitido constatar que a partir del siglo IV en África y Antioquía, y en la Gallia a mediados del siglo $V$, existe una concentración de riqueza y poder en manos de muy pocos aristócratas - potentissimi- y un cambio en la forma del patrocinio personal. La cada vez mayor fuerza de los principales, honorati o illustris es debida al control sobre los senados locales, al nombramiento de los magistrados locales y a la supervisión en la percepción de los impuestos 119 . A esta situación hay que sumar que muchos individuos pertenecientes a la clase aristocrática, que podían a su vez ocupar un cargo en la administración pública y ser grandes propietarios, pasaron a ostentar importantes cargos religiosos a partir de su conversión, como por ejemplo obispados. Quizá uno de los ejemplos más evidentes es el de Sidonio Apollinar, que tras haber sido prefecto de Roma, en el 47I pasó a ser obispo de Clermont. Arqueológicamente este panorama puede documentarse por el abandono de ciertos sectores urbanos, la ampliación y reestructuración de determinadas grandes domus y la mayor atención que se presta a algunas construcciones rurales, a pesar de que otras son abandonadas.

En este análisis sobre el porqué de las transformaciones se debe tener en cuenta el problema de que plantea la readministración o reorganización de la propiedad. Ello es debido a que existe una tendencia generalizada entre los historiadores a considerar que a partir del Bajo Imperio se da una concentración en la organización de las propiedades hecho que explica la disminución de los centros de explotación ${ }^{120}$. Este fenómeno ha podido ser constatado en la Gallia Narbonensis a partir de numerosos ejemplos bien conocidos ${ }^{121}$. Si bien hay que tener una cierta prudencia en la afirmación de que se asiste a una reducción del número de uillae y a un aumento de las aglomeraciones de hábitat dedicadas a la explotación, puesto que cada región debió responder a comportamientos diferentes dependiendo de la extensión de los latifundia y de la ubicación del núcleo habitativo, esencialmente en la pars urbana y la rustica.

El problema planteado esta en muy estrecha relación con la propiedad y cómo esta cambia de manos. Es muy posible, tal como se

\footnotetext{
116 A. H. M. Jones, "Church Finance in the Fifth and Sixth Centuries", Journal of Theological Studies (Oxford, 1960), pp. 84-94.

II7 M. Bourin y A. Durand, "Église paroissiale, cimitière et castrum en bas Languedoc", Fixot and Zadora-Rio (eds.), pp. 98-106. Ver en el mismo volumen M. Riu y P. Valdepeñas, "El espacio eclesiástico y la formación de las parroquias en Cataluña de los siglos IX al XII", pp. 57-67, cf. pp. 58, 60 y 61.

118 Este fenómeno ha sido analizado en numerosos artículos por D. Vera. Uno de los más recientes D. Vera, "Dalla 'villa perfecta' alla villa di Palladio: sulle transformazioni del sistema agrario in Italia fra principato e dominato", Athenaeum 83.1, 1995, pp. I89-2 I2 y 83.2, pp. 331-356.

119 Ellis, "The End of the Roman House", p. 573.

120 Leveau, Sillières y Vallat, Campagnes de la Mediterranée romaine. Occident, p. 269.

I2I Pellecuer, "Villa et domaine", p. 280, donde se trabaja estadísticamente con datos arqueológicos de 7 I uillae ubicadas en la misma prouincia.
} 
desprende de la lectura de Orosio que como consecuencia del absentismo de los antiguos o nuevos propietarios muy pocas uillae defendieran su propiedad, provocando una situación de beneficio en la redistribución de los bienes obtenidos para los colonos, a pesar de trabajar para un nuevo dominus.

Los estudios y ejemplos señalados hasta ahora permiten hipotetizar sobre el cambio que se produce -visiblemente en Occidentea finales de la antigüedad tardía y a principios de la alta Edad Media en el sistema de explotación. Cambio que se había iniciado ya en época imperial, momento a partir del cual se pasa gradualmente de una gestión autónoma de cada explotación a un mucho más complejo y articulado ${ }^{122}$. Es muy posible que a partir de la antigüedad tardía, el sistema de explotación patrimonial sea absorbido, de forma más o menos definitiva, por comunidades rurales mucho más dinámicas, tal como se ha podido demostrar en algunas regiones de la Gallia ${ }^{123}$, en Hispania ${ }^{124}$ e Italia ${ }^{125}$. De ahí vendría muy probablemente la ambigüedad de los textos, mencionados al principio, que "desvirtúan" el significado originario de la palabra uilla y permiten identificarla con una aglomeración secundaria ${ }^{126}$. Por regla general la aparición del término uilla acompañado de un nombre propio corresponde a un núcleo poblacional concreto, originario en muchos casos de una población medieval, y no a una uilla en el sentido de domus rural ${ }^{127}$.
Ejemplos de este tipo de documentación medieval se encuentran en prácticamente toda la Gallia. Sólo se menciona aquí el de Dassargues (Lunel, Hérault) ${ }^{128}$, lugar conocido por uilla Adacianicus por una carta del año 788 concerniente a una donación con toda la descripción del hábitat. Las prospecciones y excavaciones llevadas a cabo han documentado un hábitat disperso de época imperial, con un empuje muy importante durante la antigüedad tardía como hábitat agrupado cuya evolución conlleva una continuidad ininterrumpida hasta la aglomeración medieval. Será a partir del siglo $X I$ que el lugar empieza a decaer hasta el siglo XIl que será abandonado. No existe por tanto nada que pueda poner en relación este topónimo de uilla Adacianicus con la existencia de una uilla característica de época romana o de la antigüedad tardía.

Al principio de estas páginas se ha aludido a la fragilidad de los textos en el momento de definir el significado de la palabra uilla durante la antigüedad tardía. Lo mismo ocurre con la utilización en los textos medievales. Este término - uilla- debe ser tratado con mucha precaución puesto que desde un punto de vista semántico, puede referirse a otro tipo de concentración de hábitat, más en relación a pequeños núcleos urbanos y no de hábitat rural, tipo residencia o establecimiento.

De todas formas hay que destacar que a pesar de los profundos cambios, reestructura-

122 Ortalli, "La fine delle ville romane: esperienze locali e problemi generali”, p. 17.

123 Leveau, Sillières y Vallat, Campagnes de la Mediterranée romaine. Occident, p. 269.

124 Para la Tarraconensis, cf. Chavarría, "Transformaciones arquitectónicas de los establecimientos rurales de la antigüedad tardía en el nordeste de la Tarraconensis" y Ead. "Els establiments rurals del llevant de la Tarraconesa durant l'antiguitat tardana: transformacions arquitectòniques i funcionals". La Carthaginensis se analiza en Sonia Gutiérrez, La Cora de Tudmir. De la Antigüedad tardía al mundo islámico. Poblamiento y cultura material (Collection de la Casa de Velázquez, 57, Madrid-Alicante, 1996).

125 Véase Rossi, "I casi di Pontevico, Nuvolento e Breno", p. 40, a partir de algunos ejemplos de la zona de Brescia y retomando las sugerencias de G.P. Brogiolo, "La campagna tra tardoantico e altomedioevo", Archeologia in Lombardia (Milán, 1982), p. 214.

126 La propuesta de C. Mercier y C. Raynaud, "L'habitat rural en Gaule meditérranée aux Vle-VIle siècles. Approche régionale et étude de cas", Les campagnes de la France méditerranéenne dans l'Antiquité et le haut Moyen-Âge (Documents d'Archéologie Française 42, París, 1994), pp. 198-204, cf. p. 198, resulta en este punto muy sugestiva y quizá es una de las vías a seguir tratando para resolver el problema de este trabajo.

127 Así se demuestra en el estudio de Heinzelmann, "Villa d'après les oeuvres de Grégoire de Tours", p. 6I.

128 Mercier y Raynaud, "L'habitat rural en Gaule meditérranée aux Vle-VIle siècles. Approche régionale et étude de cas", pp. I98-204, con todo el estudio sobre la evolución del yacimiento. 
ciones y transformaciones de las uillae, el concepto mismo de vida y explotación por parte de las aristocracias, debió prevalecer durante mucho tiempo incluso bien entrada la época medieval. Esta afirmación viene dada gracias a un claro ejemplo de la Península Ibérica: el testamento del rey Alfonso III (905) donde se menciona entre sus propiedades la uilla Liño, junto a sus palacios, baños y la iglesia de San Miguel ${ }^{129}$.

129 Arce, "Otium et negotium: the great estates, 4th-7th century", p. 32. 


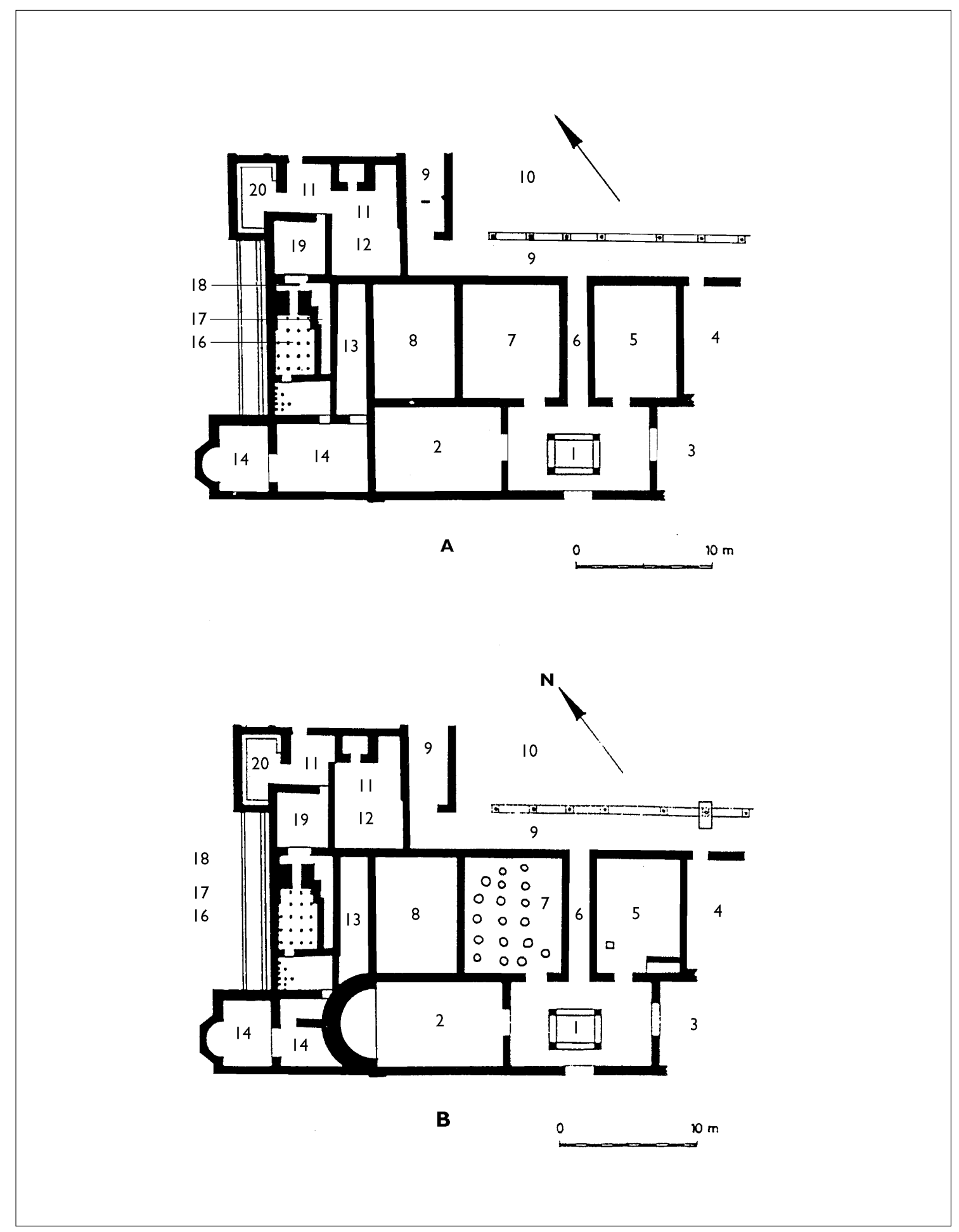

Fig. I. Torre Llauder (Mataró, Barcelona), planta de la uilla (según M. Prevosti y F. Clariana, 1988). A: planta de época severa; B: planta durante la antigüedad tardía. 


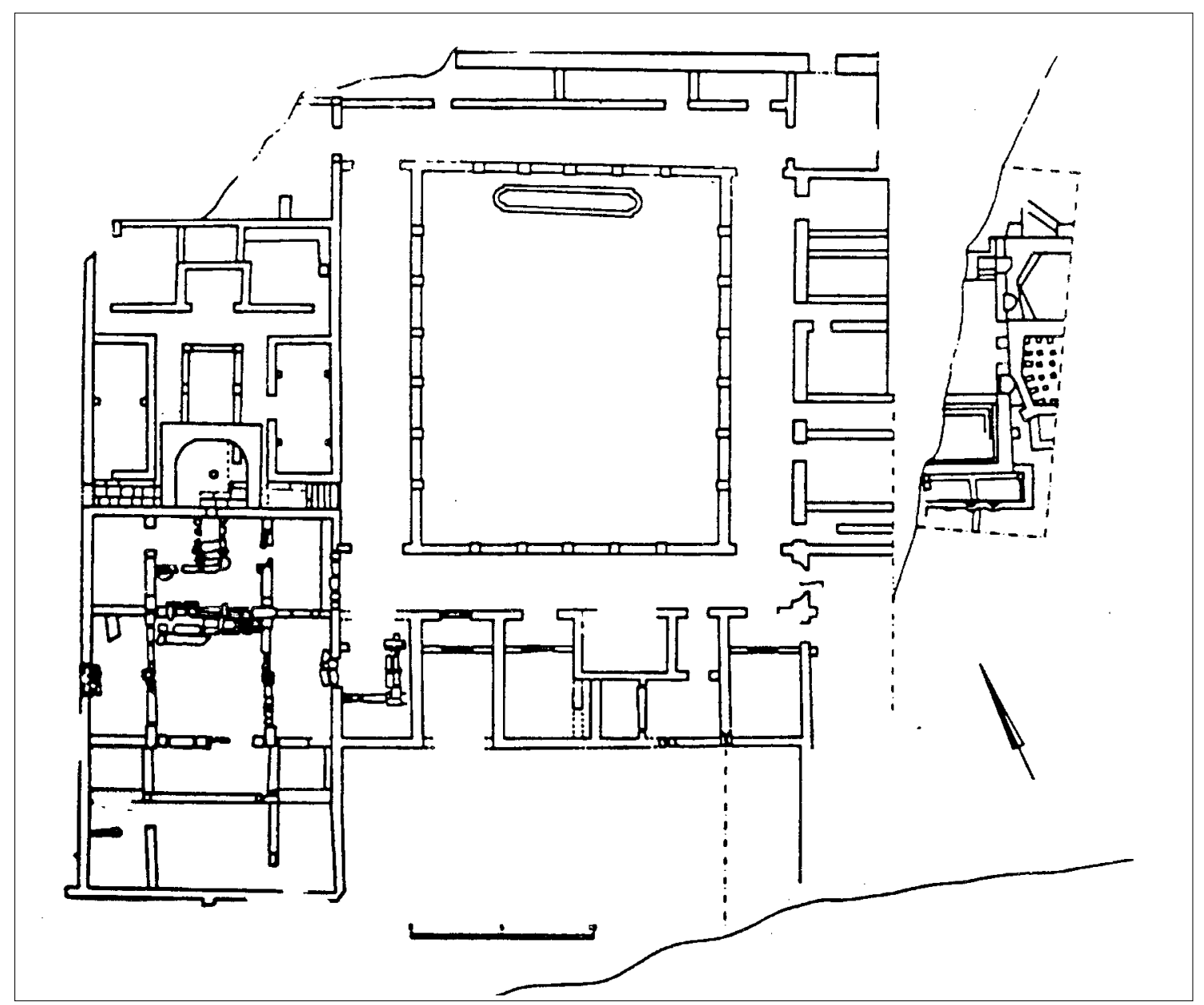

Fig. 2. Villa Fortunatus (Fraga, Huesca), planta general de las estructuras (según F. Tuset, publicada por P. de Palol, 1989).

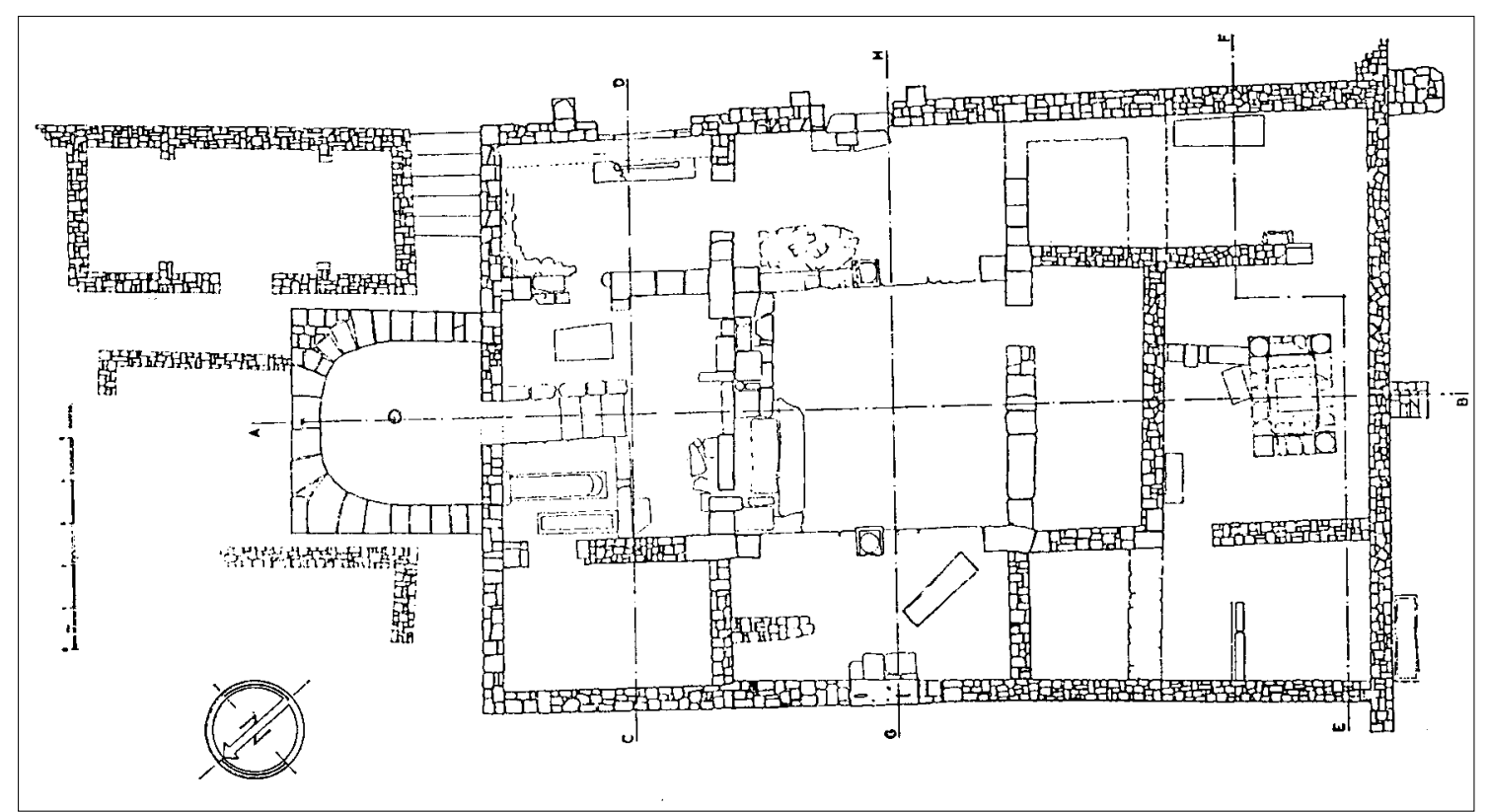

Fig. 3. Villa Fortunatus (Fraga, Huesca), planta general de la iglesia en su última fase (según R. Puertas, 1972). 


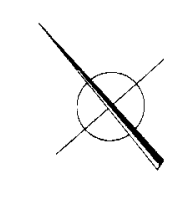

When

6. Charpentice, 1989

A
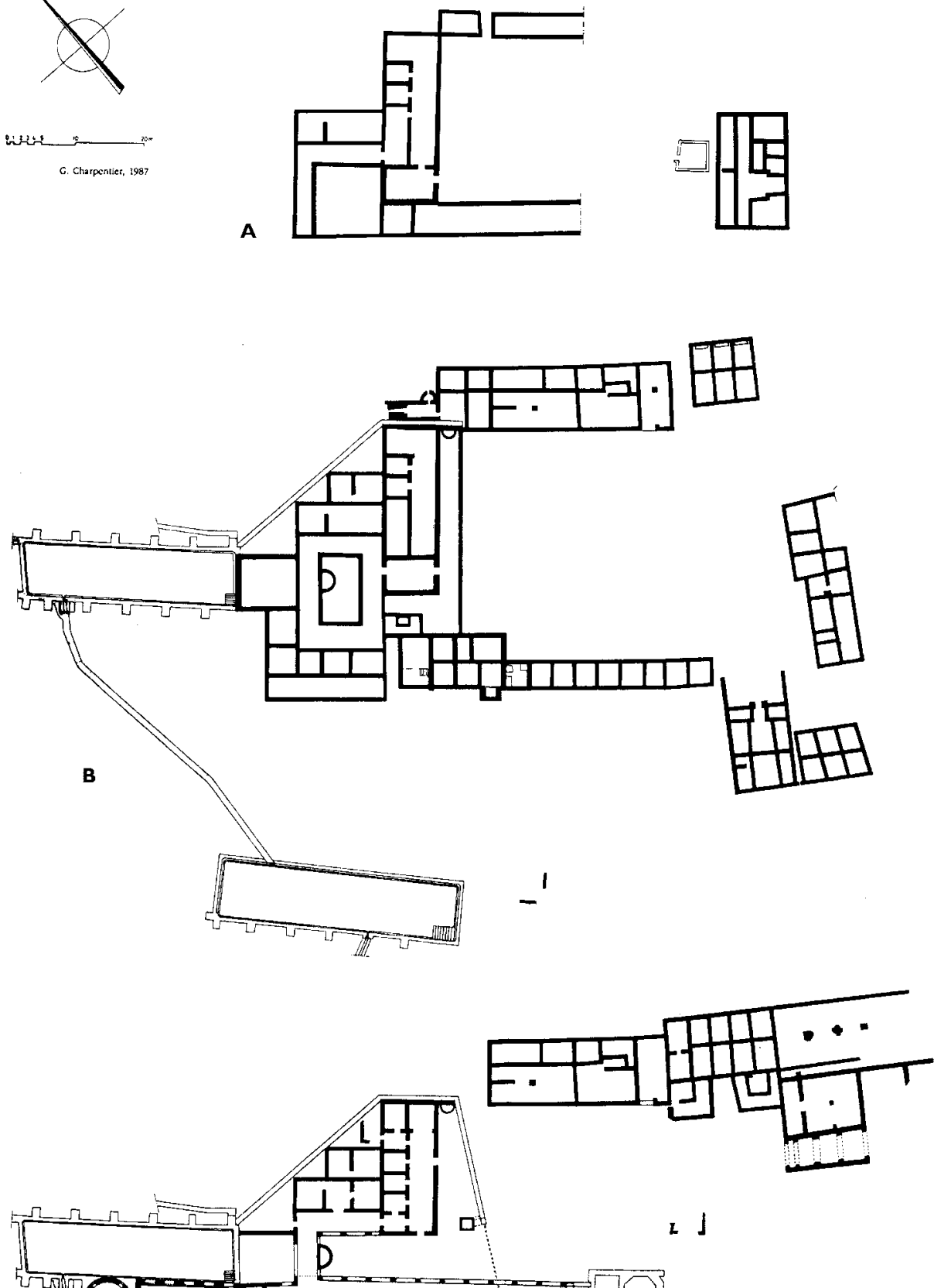

1

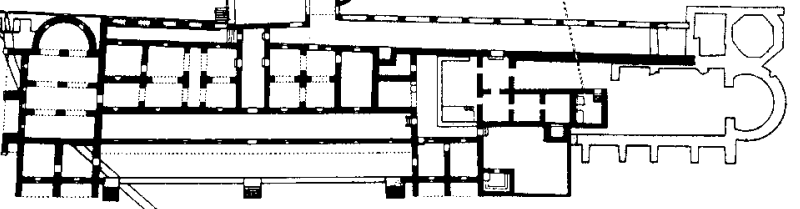

c
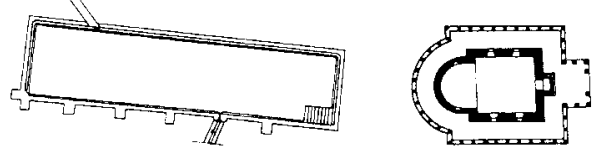

Fig. 4. São Cucufate (Beja, Portugal), planta de la uilla (según J. de Alarcão, et alii, 1990). A: uilla I y sector rústico; B: uilla II y fase II del sector rústico; C: uilla III y sector rústico (siglos IV y V). 


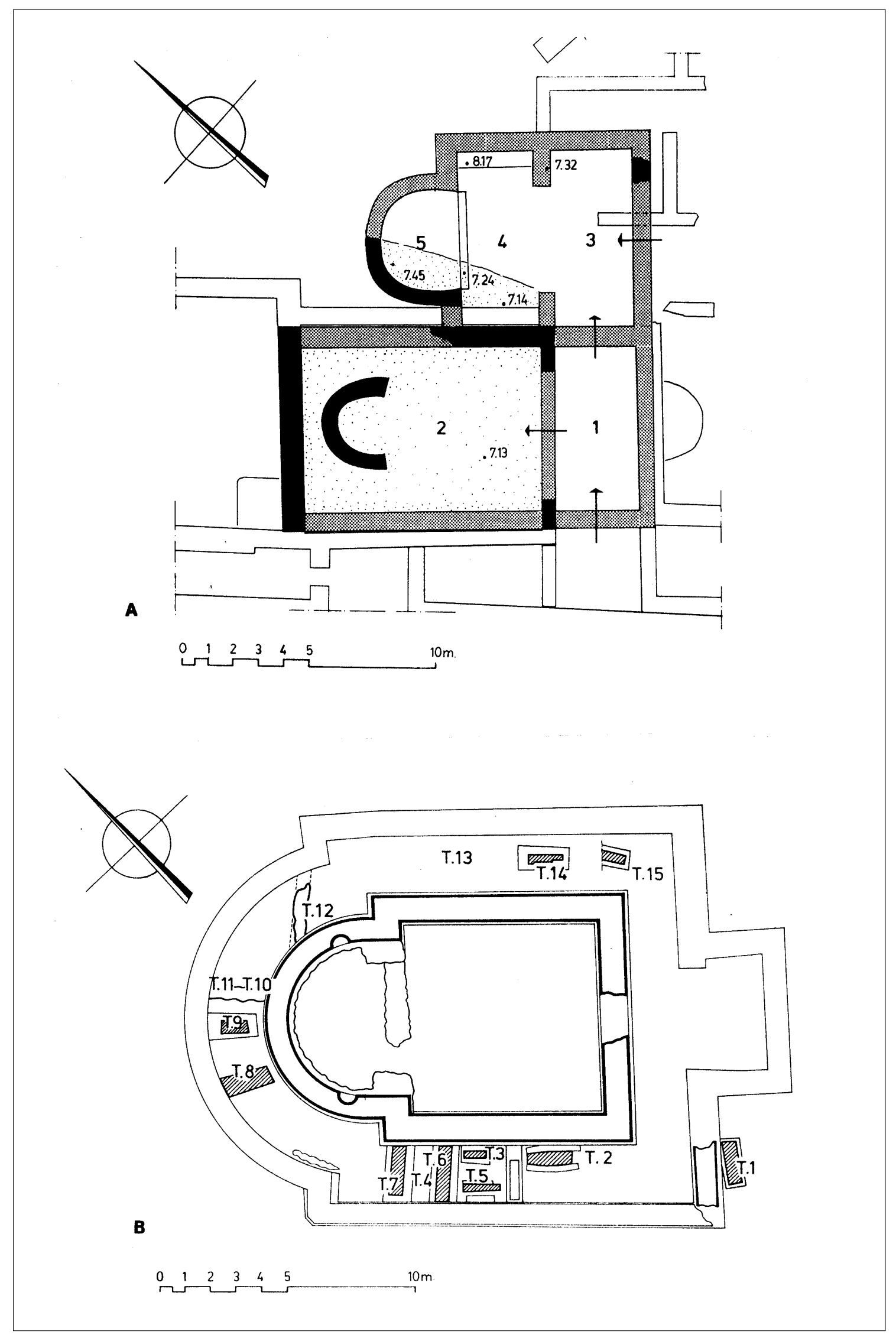

Fig. 5. Sao Cucufate (Beja, Portugal (según J de Alarcao, et alii, 1990). A: planta de los lugares de culto primitivos; B: planta de las tumbas alrededor de la cella del templo. 


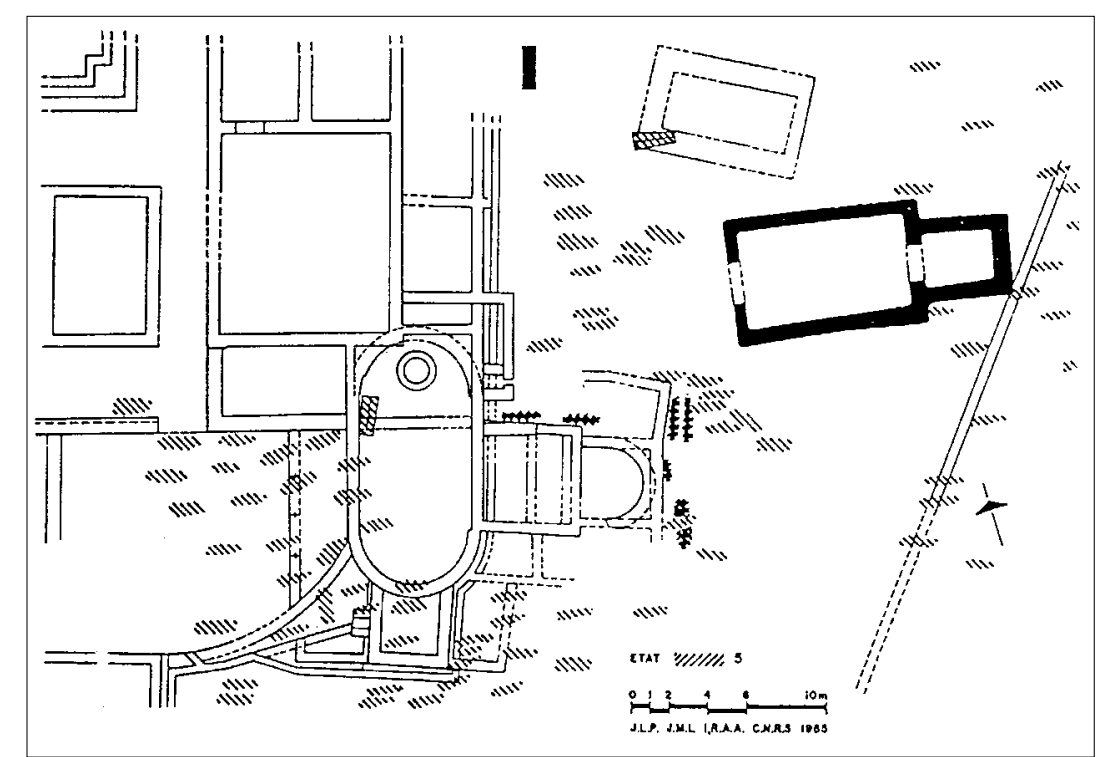

Fig. 6. Séviac (Montreal du Gers, Gers) (según J. Lapart y J.-L. Paillet, 1985). Planta del sector paleocristiano de la uilla.

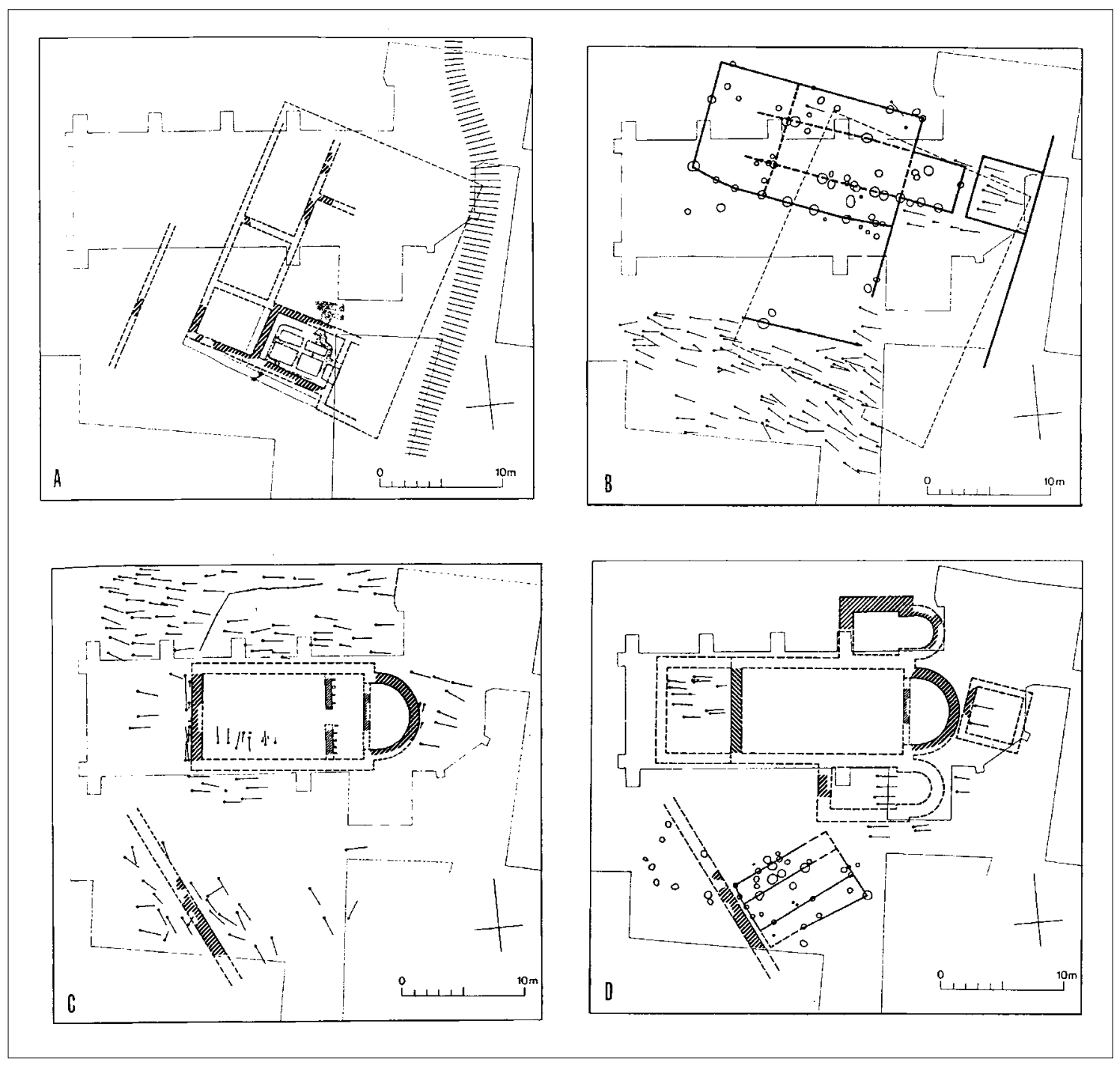

Fig. 7. Satigny (Ginebra) (según Ch. Bonnet, 1994). A: uilla del siglo IV; B: iglesia en madera y necrópolis de los siglos V y VI; C: iglesia carolingia; D: iglesia prerrománica. 


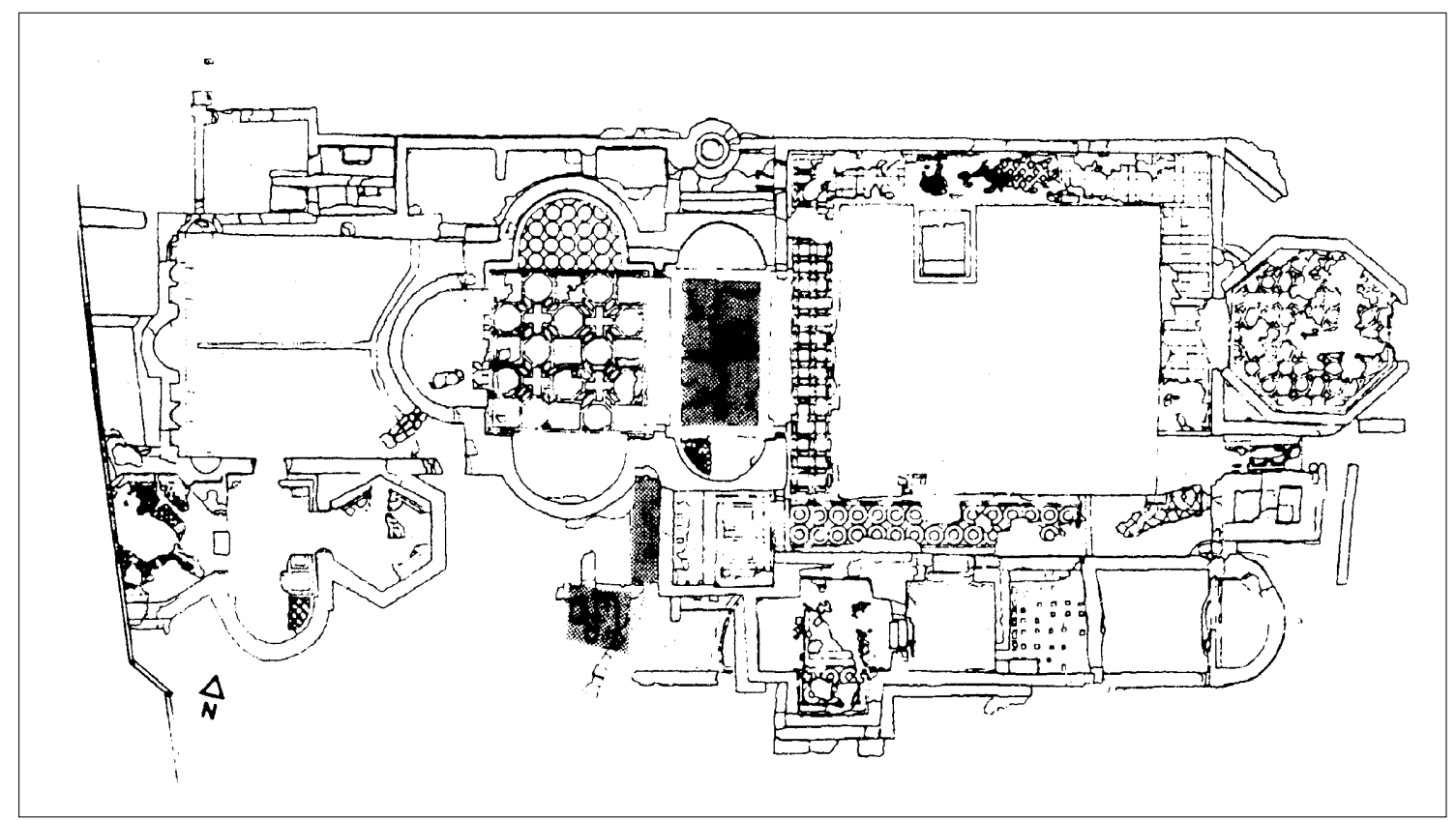

Fig. 8. Desenzano (Lago di Garda, Brescia) planta del sector A.

Punteadas las zonas funerarias (según M. Bolla, 1996).

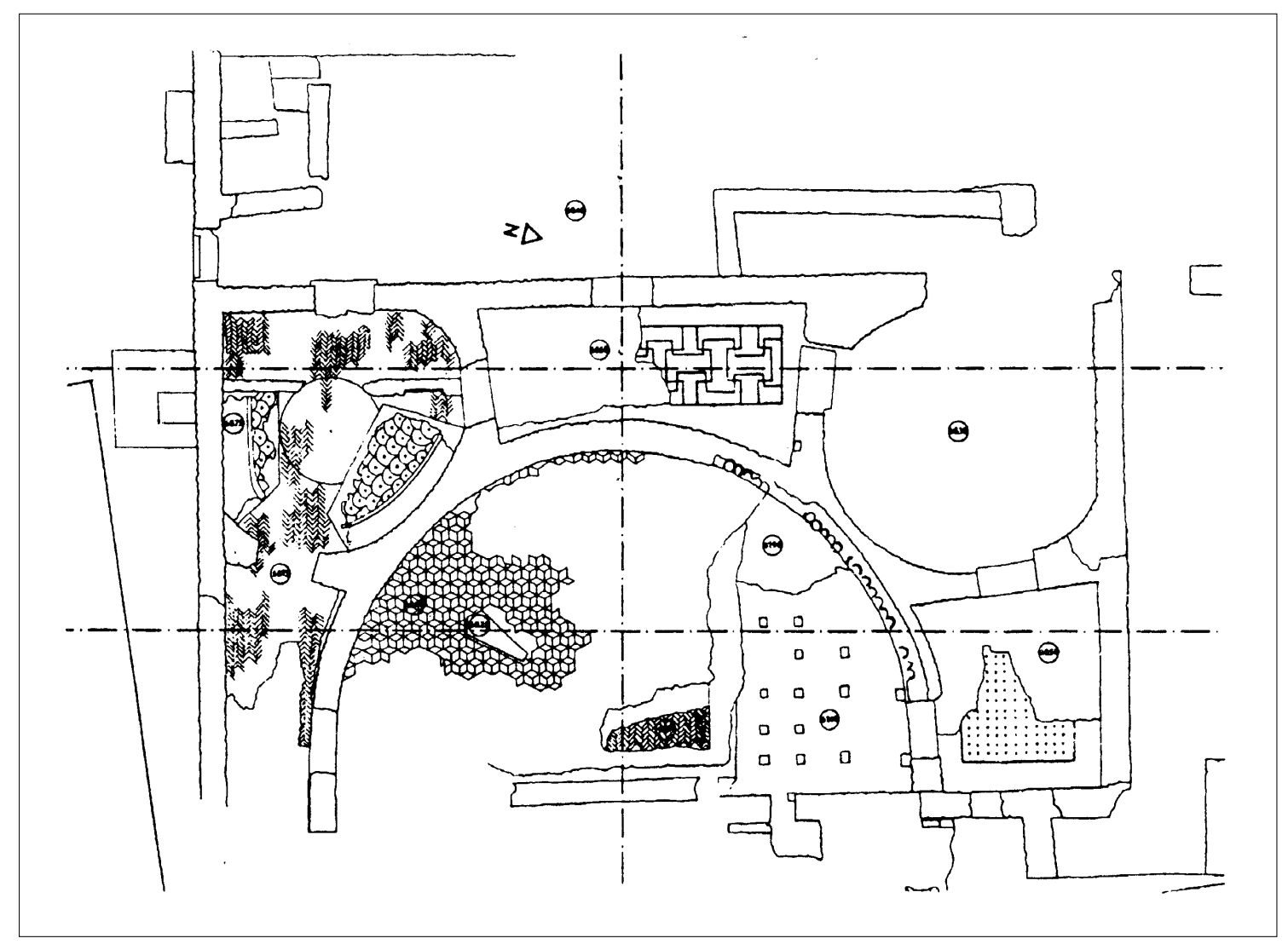

Fig. 9. Desenzano (Lago di Garda, Brescia) planta del sector B, ámbito 35, con sepultura en el ábside (según M. Bolla, 1996). 


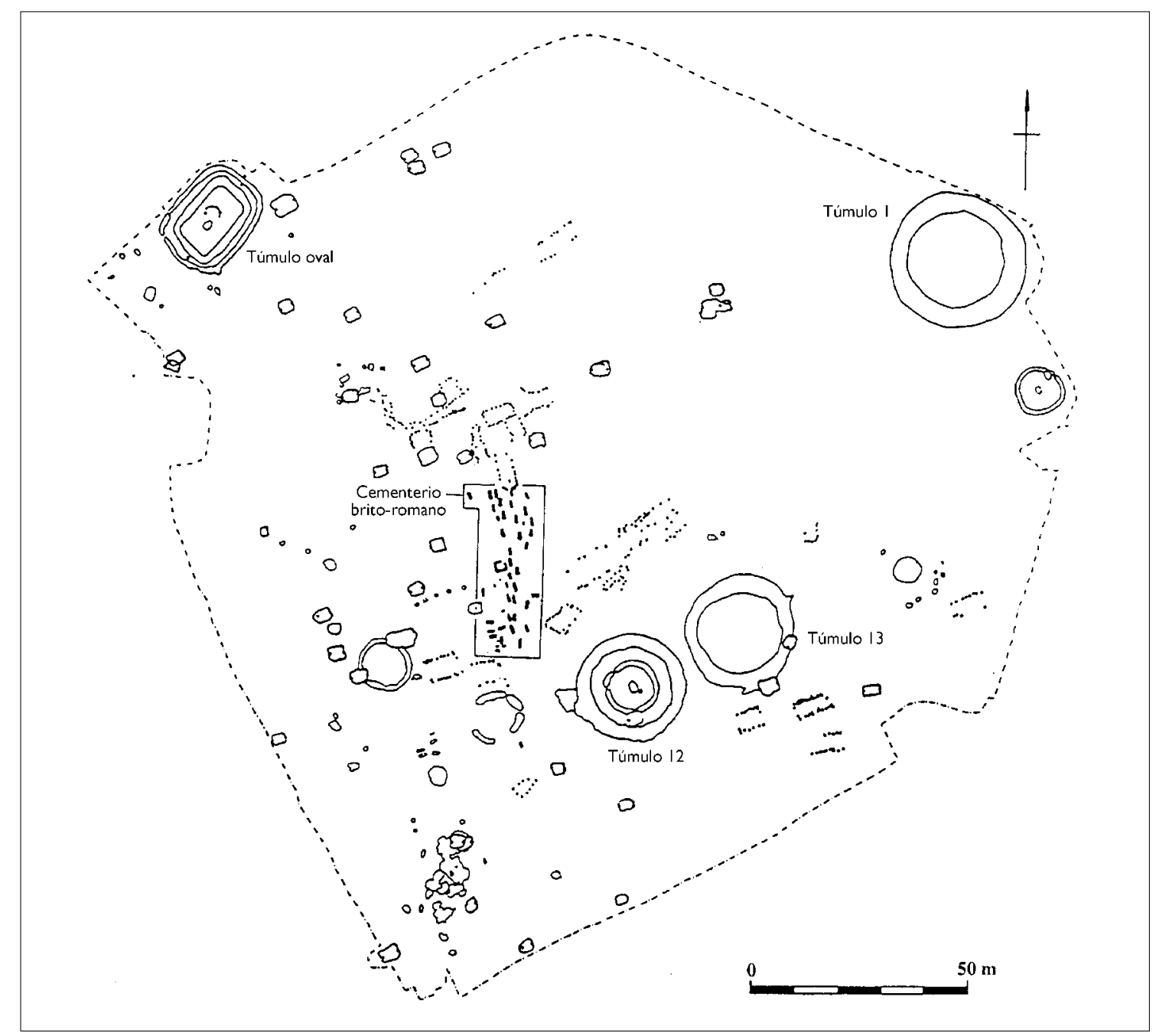

Fig. I0. 'Grotte di Catullo' (Sirmione, Brescia) planta del sector residencial. Punteadas las zonas funerarias (según M. Bolla, 1996).

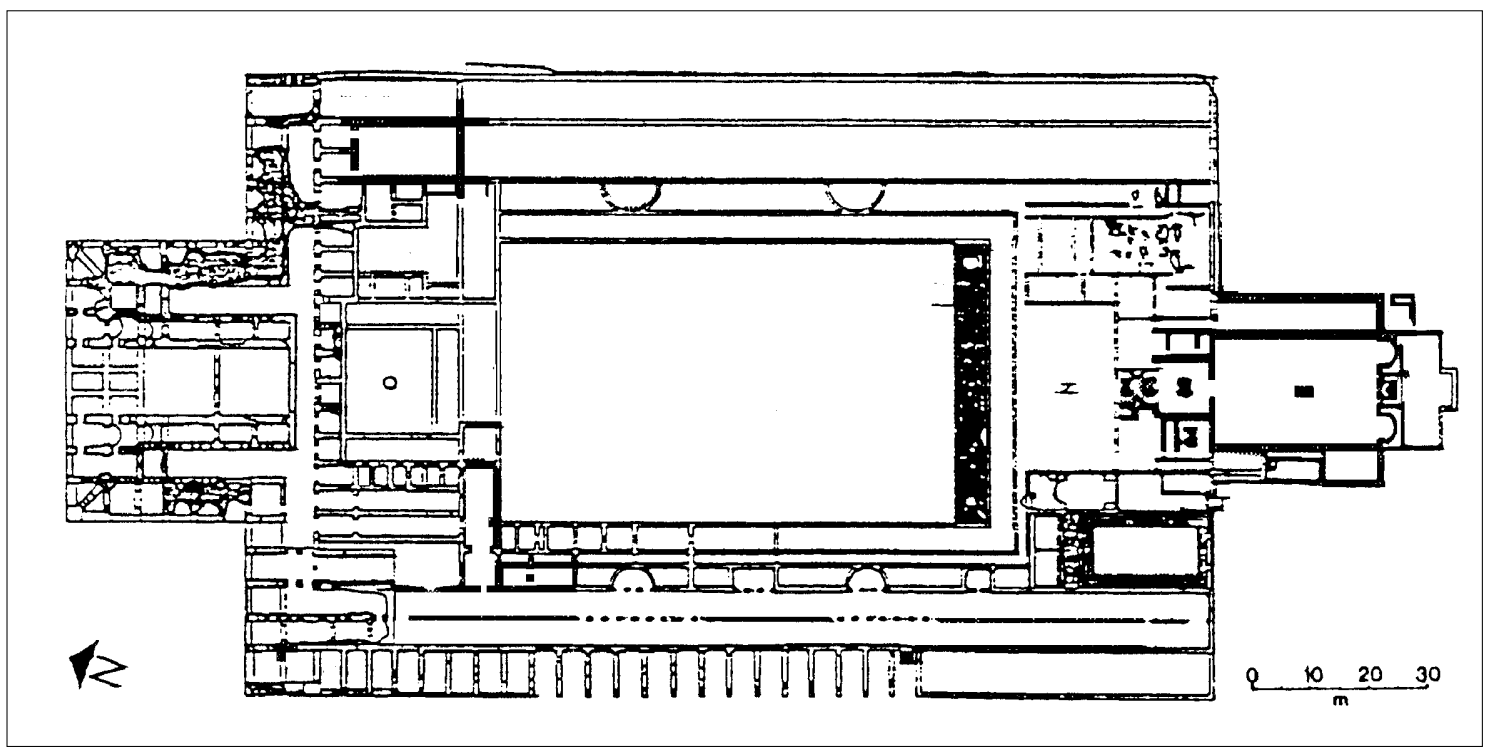

Fig. II. Barrow Hills (Oxfordshire) planta de la necrópolis y del hábitat (según A. Dodd y E. McAdam, 1995). 


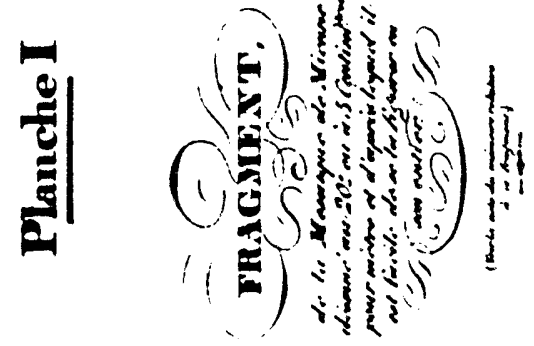

